\title{
Moral Reiativism and Reasons for Action
}

by

Robert Streiffer

B. A. Reed College, 1993

Submitted to the Department of Linguistics and Philosophy in

Partial Fulfillment of the Requirements for the Degree of

Doctor of Philosophy

at the

Massachusetts Institute of Technology

September 1999

(C) 1999 Robert Streiffer. All rights reserved.

The author hereby grants to M. I. T. permission to reproduce and to distribute publicly paper and electronic copies of this thesis document in whole or in part.

Signature of Author:

Department of Linguistics and Philosophy

Certified by:

Judith Jarvis Thomson

Professor, Department of Linguistics and Philosophy

Thesis Supervisor

Certified by:

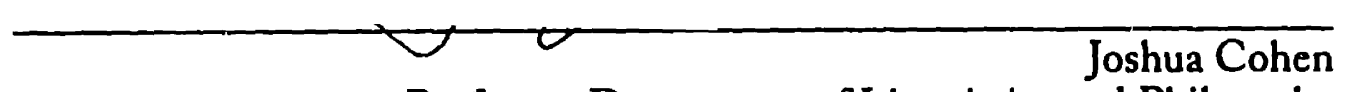

Professor, Department of Linguistics and Philosophy Professor, Department of Political Science

Thesis Advisor

Certified by:

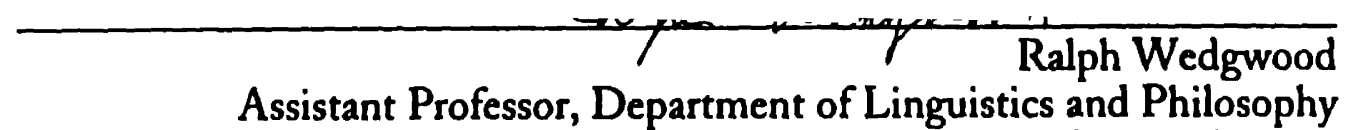

Assistant Professor, Department of Linguistics and Philosophy

Thesis Advisor

Accepted by:

Robert Stalnaker

Professor, Department of Linguistics and Philosophy Chair of the Department of Philosophy

MSSACHUSETTSTISTTUTE

OF TECHNOLOQY

\section{SEP 211999}

LIBRARIES 



\title{
Moral Relativism and Reasons for Action
}

by

\author{
Robert Streiffer
}

Submitted to the Department of Linguistics and Philosophy on July 30, 1999 in Partial Fulfillment of the Requirements for the Degree of Doctor of Philosophy in Philosophy

\begin{abstract}
There are many varieties of moral relativism. Appraiser relativism, according to which the proposition cxpressed by a moral sentence varies from context to context, is motivated by the tho' 'ght that it provides the best explanation of the intractability of fundamental moral disagreements. In response, it is standardly objected that appraiser relativism runs afoul of our linguistic intuitions about when people are contradicting one another. In Chapter One, I expand upon this objection in three ways: (i) the problematic class of intuitions is larger than has previously been noticed; (ii) three strategies that have been offered to explain away those intuitions fail; and (iii) even if we grant that appraiser relativism is true, it still would not provide us with any explanation whatsoever of the intractability of the relevant disagreements.

Agent relativism, according to which there are no universal moral requirements, is motivated by the thought that there are always reasons to comply with one's moral requirements, but that the desires to which such reasons would have to correspond are too capricious for there to be any universal moral requirements. In Chapter Two, I argue that the moral universalist is free to maintain either (i) that any fully rational, fully informed agent will have a desire that would be served by complying with what the moral universalist takes to be universal moral requirements, and so desires are not too capricious, or (ii) that a naturalistically acceptable account of reasons need not suppose that reasons are grounded in desires. Either way, the moral universalist is free to reject this motivation for agent relativism.

If desires do not provide the basis for reasons for action, what does? In Chapter Three, I give an analysis of reasons for action based on the ways in which an action can be good or bad. I argue that the analysis is preferable to two other analyses, and that it provides a promising explanation of why there are always reasons for agents to comply with their moral requirements. I conclude, however, that the analysis relies on distinctions which, despite being intuitively plausible, remain in need of theoretical justification.
\end{abstract}

Thesis Supervisor: Judith Jarvis Thomson

Title: Professor of Linguistics and Philosophy 


\section{•}




\section{Acknowledgements}

The first thing I do when I start working on a new project is to read everything I can find written on that project by my advisors, Judith Jarvis Thomson, Joshua Cohen, and Ralph Wedgwood. It has been almost invariably depressing. Not only do my views largely overlap with their views, and so it seemed to me as if I had nothing new to say, but their thinking on these things has always been much clearer than my own. Perhaps the overlap is the greatest with Judy, my first drafts always seemed like amateurish book reports on her own work.

But thankfully, I have found that if I work on things long enough, I don't agree entirely with their views. And every now and then, I can just stretch my imagination enough to pretend that that my thinking on some point is clearer than their own. Those who are familiar with them and with their work will, I hope, see their influence on my own work. I only wish there could have been more.

I would also like to extend my thanks to all of the other M. I. T. graduate students. Just about everyone has given me useful comments on some part or other of this dissertation. Special thanks go to Ishani Maitra and Andrew Botterell, who have given me very helpful comments on each and every chapter.

I also would like to thank my son, Samuel, who is now five. In addition to making my office a more pleasant to work by keeping it decorated with an ever-changing panoply of some of the cutest pictures ever drawn, he made going home a pleasure as well. And finally, I must acknowledge my debt to my wife, Catherine. Without her help and support, I probably wouldn't have made it into graduate school in the first place, much less ever gotten out of it. So it is with much love and affection that I dedicate this dissertation to her. 


\section{Table of Contents}

\section{Chapter One: Appraiser Relativism and the Reliability of our Linguistic Intuitions}

I Appraiser Relativism Defined.

2 The Alleged Explanation of the Intractability of Moral Disagreements ..............................

3 Some Counterintuitive Implications of Metaethical Relativism ...................................... I4

4 The First Two Strategies for Explaining Away our Linguistic Intuitions.........................20

5 A Test for Determining the Reliability of our Linguistic Intuitions ................................24

6 The Third Strategy for Explaining Away our Linguistic Intuitions ................................ 27

7 Appraiser Relativism, Explanation, and the Reliability of our Linguistic Intuitions.... 32

8 Summary and Concluding Remarks.

\section{Chapter Two: Agent Relativism and Reasons for Action}

I The Practicality Argument.

2 Two Arguments for Moral Universalism.

3 A Defense of the Practicality Requirement

4 The Desire Argument for Reasons Relativism

5 The Narrow Desire Argument for Reasons Relativism.

6 Summary.

\section{Chapter Three: Reasons for Action and the Ways of Being Good}

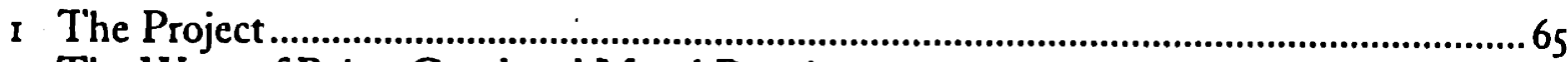

2 The Ways of Being Good and Moral Requirements .........................................................69

3 The Ways of Being Good and Reasons for Action ................................................................. 75

4 The Quick Argument for the Relevance of Morality........................................................79

5 Some Advantages of the Quick Argument for the Relevance of Morality .......................80

6 The Moral Requirements Thesis...................................................................................... 85

7 Difficulties for the Revised Reasons for Action Thesis ..................................................88

8 The Revised Argument for the Relevance of Morality .....................................................92

9 Difficulties for the Revised Argument for the Relevance of Morality .............................96

ro Summary and Concluding Remarks...................................................................................

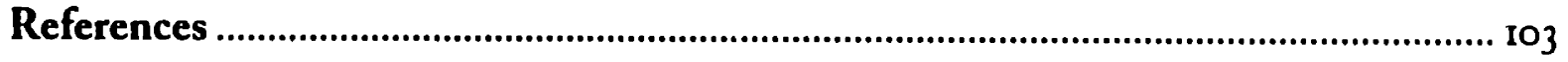


. 


\section{Chapter One \\ Appraiser Relativism and the Reliability of our Linguistic Intuitions}

\section{Appraiser Relativism Defined}

I.I Moral relativism comes in many forms, and the different forms are motivated in different ways. Appraiser relativism, according to which the proposition expressed by a moral sentence varies from context to context, is primarily motivated by the thought that it would provide the hest explanation of the actual intractability we see surrounding fundamental moral disagreements.' In response, it is standardly objected that appraiser relativism runs afoul of our linguistic intuitions about when people are contradicting one another. In this chapter, I expand upon this objection in three ways. First, I argue that the problematic class of linguistic intuitions is much larger than has previously been noticed. Second, I argue that three strategies that have been offered to explain away those linguistic intuitions fail. And third, I argue that even if we were to grant that appraiser relativism were true, it still would not provide us with any explanation whatsoever of the intractability of the relevant disagreements.

1.2 Given a sentence $S$, we can prefix 'It is not the case that' to $S$ to form what I will call its syntactic negation. The distinctive claim of the appraiser relativist is the claim that for any moral sentence and its syntactic negation, it is possible for both to be asserted truly. ${ }^{2}$ In order to avoid contradiction, then, the appraiser relativist needs to tell a story according to which the logical form of moral sentences differs from their grammatical

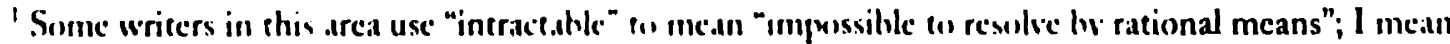
nothing more than "hard in resolve."

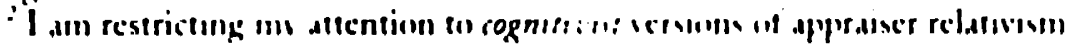


form, and the most plausible story for the appraiser relativist to tell is that the moral properties that figure in the propositions expressed by moral sentences have an extra argument place whose value varies from context to context. So, although you might have thought that the property of being immoral was a one-place property, had by some actions and not by others, in fact there is no such one-place property. Rather there is the two-place relation of being immoral relative to a morality: Actions bear this relation to some moralities, but not to others. Compare: there is no one-place property of being tall, had by some people and not by others. Rather, there is the two-place relation of being tall relative to a comparison class. People bear this relation to some comparison classes, but not to others.

There are two versions of appraiser relativism prominent in the literature. Shifting to the formal mode, and letting

(S) Lying is immoral

be our representative moral sentence, we can define the first version of appraiser relativism as follows:

Speaker Relativism: If $M$ is the morality belonging to the speaker in context $C$, then the proposition that $(\mathrm{S})$ expresses in $\mathrm{C}$ is that lying is immoral relative to $\mathrm{M}$.

I call this "Speaker Relativism" because it says that the morality that figures in the proposition expressed is always the morality of the speaker. ${ }^{3}$

We can define the second version of appraiser relativism as follows:

Salience Relativism: If $M$ is the morality salient to the speaker in context $C$, then the proposition that (S) expresses in $\mathrm{C}$ is that lying is immoral relative to M.

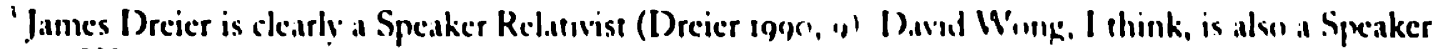
Relativive (Wong 1084, ; ; ).
} 
I call this "Salience Relativism" because it says that the morality that figures in the proposition expressed is always the morality salient to the speaker. ${ }^{4}$ When I use the term "Appraiser Relativism", I should be understood as making a claim that applies to both Speaker Relativism and Salience Relativism.

A few remarks about the definitions are in order. First, I am not going to say much about what a morality is, or as what marks one morality rather than another as belonging to or being salient to a speaker. I'll just be using moralities as placeholders for whatever it is that the relativist thinks that moral properties are relative to. For all I've said, the morality that figures in the proposition a speaker asserts might be a function of the moral attitudes predominant in his society, it might be a function of what would be in the interests of his society, or it might be a function of his own moral attitudes or a function of what would be in his own interests. On such a broad understanding of what might count as a morality, Speaker Relativism includes what is usually known as subjectivism, as well as traditional versions of appraiser relativism according to which the morality that figures in the proposition asserted is a function of facts about the speaker's culture or society. Second, for the purposes of both definitions, propositions are to be individuated in terms of their truth-conditions. Appraiser Relativism is first and foremost a view about the truth-conditions of moral sentences; it is not itself a claim about what speakers intend to be saying when they utter a moral sentence. ${ }^{5}$

\footnotetext{
${ }^{4}$ In (Harman 1975), Harman clearly wants to allow that a person can use a moral sentence to make assertions about moralities other than his own. In (Harman and Thomson 1996), Harman does not explicitly say whether he thinks that the morality that figures in a person's assertion is always the speaker's own morality, but he does draw a close analogy between his metacthical view and the view that when someone asserts a sentence of the form 'The mass of $X$ is $M$ ', he thereby asserts the proposition that the mass of $\mathrm{X}$ is $\mathrm{M}$ in relation to the spatio-temporal framework that was "conspicuous to the person making the judgment" ([italics added] Harman and Thomson 1996, 4). The analogy suggests that on Harman's metaethical view the morality that figures in the proposition asserted will be the one conspicuous, or in my terminology, salient, to the person making the assertion. For a different interpretation, sec Thomson's reply in (Harman and Thomson 1996).

${ }^{5}$ Harman is clear on this point. He says that his view is about how we must understand moral sentences "for the purpeses of assigning truth-conditions", and he cmphasiees that his version of relutwism "is no more a claim ahout what people mean by their moral judgments than relativism abour m...

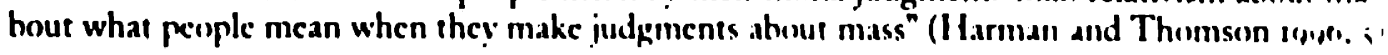


Both Speaker Relativism and Salience Relativism are forms of cognitive appraiser relativism. They are forms of cognitivism because, according to them, $(\mathrm{S})$ expresses a proposition, although it will express different propositions in different contexts. The obvious contrast here is with noncognitivism, according to which (S) does not express a proposition, but rather expresses a prescription or an emotion. Both versions of relativism are forms of appraiser relativism (Lyons 1976, 21I-212) because, according to them, the morality that figures in the proposition expressed is determined by facts about the speaker doing the appraising, rather than by facts about the agent performing the action being appraised.

2.I So, how does the Appraiser Relativist explain the intractable disagreements we see surrounding fundamental moral issues?

Well, evidently, the parties to these disagreements think that their assertions are inconsistent; why else would they have started arguing in the first place? But so long as they think their assertions are inconsistent, they cannot consider the disagreement resolved until one of their assertions has been shown to be false. But according to the Appraiser Relativist, this cannot be done because both parties to these disagreements are in fact speaking truly. How is that possible? Well, according to the Appraiser Relativist, the proposition expressed by a moral sentence varies from context to context, and so it will turn out that for any moral sentence and its syntactic negation, it is possible for both sentences to be asserted truly. ${ }^{6}$

"Many relativists would not subscribe to this claim as stated on the grounds that some moral sentences are analytic. If a moral sentence is analytic, then its syntactic negition cannot be truly asserted and, a fortiori, both it and its syntactic negation cannot be truly asserted. Harman, for exaniple, silys that 'Muriter is wrong' is analytic because "murder" is simply defined as "wrongful killing" (Harman and Thornson rewen. 9). But because my objections do not rely on such counterexamples, it will not he unfair to simplify the discussion by ignoring this complication. 
The Appraiser Relativist then argues that it is precisely in those intractable moral disagreements, where the parties seem reasonable and well-informed, that we often find two people speaking truly, even though one person is asserting a moral sentence and the other person is asserting that sentence's syntactic negation. In short, the Appraiser Relativist's explanatory claim is that so long as both parties adhere to the view that their assertions are inconsistent, neither party will consider the disagreement resolved until they have shown the other's assertion to be false. But because both assertions are true, this cannot be done.

The question with which I will be concerned, then, is whether the Appraiser Relativist's explanatory claim provides the best explanation of the intractable moral disagreements we see surrounding fundamental moral issues.

An explanatory claim can be objected to in two ways. First, it can be objected to by arguing that the truth of the explanans does not fit in well with other claims we find independently plausible. For example, it may be granted that the trajectories of mediumsized dry goods moving at slow speeds would be explained by the truth of Newtonian physics. Nonetheless, because Newtonian physics doesn't fit in well with other claims for which we have independent evidence, we have independent grounds for rejecting any explanatory claims made on its behalf. Second, an explanatory claim can be objected to by arguing that even if the explanans were true, its truth would still not explain the truth of the explanandum in question. For example, it may be granted that the claim that I am wearing a tie fits in perfectly well with other claims we find independently plausible. Nonetheless, we may doubt that the truth of the claim that I am wearing a tie is what explains why I have hazel eyes. The truth of the claim that I am wearing a tie simply doesn't seem to stand in any explanatory relation to the truth of the claim that I have hazel eyes.

Let us now turn to an objection of the first kind: that Appraiser Relativism does not fit in well in with other claims we find independently plausible. 


\section{Some Counterintuitive Implications of Appraiser Relativism}

3.I As many philosophers have become frustrated with the inability of noncognitivism to explain how moral sentences figure in truth-ascriptions and beliefascriptions, they have turned to some form of cognitivist relativism as an attractive alternative. James Dreier, for example, emphasizes this advantage of his version of Appraiser Relativism:

On my proposed analysis, sentences containing moral terms straightforwardly express propositions - though which propositions they express will vary with the context. So I can simply say that such sentences embed into the relevant contexts just as any other indexical sentences do. (Dreier 1990, 15)

Setting aside the question of whether noncognitivism can explain how moral sentences einbed into the relevant contexts, the way in which Appraiser Relativism predicts that moral sentences will embed into the relevant contexts is highly counterintuitive. Let me illustrate this, first, by considering four counterintuitive implications shared by both Speaker Relativism and Salience Relativism, and second, by looking at one counterintuitive implication specific to each form of relativism.

To see the first counterintuitive implication common to both Speaker Relativism and Salience Relativism, suppose Albert utters

(S) Lying is immoral.

And suppose that upon hearing Albert's assertion, Bertrand utters

(SI) That's true. Lying is immoral.

We have the intuition that the fact that Bertrand asserted $\left(S_{x}\right)$ in response to Albert's assertion of $(\mathrm{S})$ implies that the proposition to which Bertrand ascribed truth by uttering 'That's true' is identical to the proposition that he then went on to assert by uttering 'Lying is immoral'. But this intuition is inconsistent with both Speaker Relativism and Salience Relativism. For it may have been that Albert and Bertrand had different 
moralities, or that different moralities were salient to them when they made their assertions, in which case the proposition to which Bertrand ascribed truth by uttering 'That's true' is different from the proposition that he then went on to assert by uttering 'Lying is immoral'.

To see the second and third counterintuitive implications, suppose that Albert and Bertrand both utter

(S) Lying is immoral.

We have the intuition that Albert and Bertrand asserted the same proposition. But again, this intuition is inconsistent with Speaker Relativism and Salience Relativism. For it may have been that Albert and Bertrand had different moralities, or that different moralitics were salient to them when they made their assertions, in which case the propositions asserted are different.

A also have a third intuition, related to the second, that the fact that both Albert and Bertrand uttered (S) implies that both Albert and Bertrand asserted the proposition that lying is immoral. But this, too, is inconsistent with both forms of relativism. If, according to Appraiser Relativism, the fact that they both uttered (S) does not imply that Albert and Bertrand asserted the same proposition (as we saw in the previous paragraph), then a fortiori, according to Appraiser Relativism, the fact that they both uttered (S) does not imply of any proposition that they both asserted it. A fortiori, according to Appraiser Relativism, the fact that they both uttered (S) does not imply of the proposition that lying is immoral that they both asserted it.

These last two counterintuitive implications are instances of a broader difficulty for Appraiser Relativism. This broader difficulty is simply that Appraiser Relativisın carves up the space of moral propositions in a counterintuitive way, associating a moral sentence such as 'Lying is immoral', not with the one proposition that lying is immoral, but rather 
with an infinite number of propositions. This means that not only will Appraiser Relativism yield counterintuitive implications for cases involving when two people said the same thing, it will also yield counterintuitive implications in cases involving when two people believed the same thing, or feared the same thing, or desired the same thing, or hoped for the same thing, and so on, down the list of propositional attitudes.

The fourth counterintuitive difficulty, the standard objection to Appraiser Relativism, is that it conflicts with our intuitions about when people's assertions are inconsistent. Whenever two people are arguing and one of them utters a moral sentence that does not, on its face, contain any context sensitive terms such as indexicals or demonstratives, and the other person utters that sentence's syntactic negation, the two people look for all the world as if they are contradicting one another. David Lyons puts the point nicely:

The judgments made [by people engajing in moral disagreement] appear to be logically incompatible. ... Appearances can be misleading, of course, but the relevant considerations are not negligible; they involve not merely surface grammar but also the conviction shared by laymen and philosophers that only one of these [assertions] could possibly be right. (Lyons 1976, 210)

3.2 Consider now a counterintuitive implication that is specific to Speaker Relativism. Consider how $\left(\mathrm{S}_{2}\right)$ embeds in $\left(\mathrm{S}_{3}\right)$ :

(S2) Albert is taller than me

$\left(\mathrm{S}_{3}\right)$ Bertrand believes that Albert is taller than me.

The proposition expressed by $\left(\mathrm{S}_{2}\right)$ in a context will be, in part, about the speaker of that context, and this remains true even when $\left(\mathrm{S}_{2}\right)$ occurs as part of a belief ascription. ${ }^{7}$ Thus,

\footnotetext{
'David Kaplan has argued persuasively for a view of indexicals according to which any occurrence of 'me' always refers to the speaker, no matter what operators precede the occurrence in a sentence. A forfiori, the embedded occurrence of ' $m$ ' in $\left(\mathrm{S}_{3}\right)$ refers to the speaker, even though it is preceded by the 'Bertrand believes that' opera:or. Sec (Kaplan r977).
} 
the proposition that $\left(S_{3}\right)$ expresses in a context is, in part, about the speaker of that context, even though the term that refers to the speaker, 'me', occurs within the 'believes that' operator.

Analogously, if Speaker Relativism is true, then the proposition expressed by (S) Lying is immoral

in a context will be, in part, about the morality of the speaker of that context, and this will remain true even if (S) occurs as part of a belief ascription. So Speaker Relativism implies that when (S) is embedded into a belief ascription such as

$\left(\mathrm{S}_{4}\right)$ Bertrand believes that lying is immoral

the proposition that $\left(\mathrm{S}_{4}\right)$ expresses in a context will be, in part, about the speaker's morality. Thus, Speaker Relativism implies that when a speaker asserts $\left(\mathrm{S}_{\mathbf{4}}\right)$, the speaker thereby ascribes a belief, viz., the belief that Bertrand believes that lying is immoral relative to the speaker's morality, to Bertrand that is in part ab sut the speaker's morality. But that seems manifestly false. Intuitively, a speaker's assertion of $\left(\mathrm{S}_{4}\right)$ could be true even if Bertrand had no beliefs about the speaker's morality.

3.3 Let me now draw your attention to an intuition, appealed to by Judith Thomson against Gilbert Harman in (Harman and Thomson 1996), which causes a problem for Salience Relativism.

Recall that according to Salience Relativism, the morality that figures in the proposition expressed by a moral sentence in a context is the morality that was salient to the speaker of the context. So if Salience Relativism is true, it ought to be possible for a speaker to utter a moral sentence, and to thereby assert that something is moral or immoral relative to someone else's morality. But what would such a context be like? I 
know of no relativist who actually describes such a context, but Thomson suggests, plausibly enough, that a Salience Relativist might have us look at contexts in which one person is reporting on someone else's morality (Harman and Thomson 1996, 203-204).

As Thomson goes on to stress, however, people do not normally assert that something is moral or inmoral relative to someone else's morality by uttering a moral sentence; rather, they do so by uttering a larger sentence in which the moral sentence is embedded. For example, if I want to report on Albert's morality, I would utter a sentence such as:

(S5) Albert believes that lying is immoral.

and it isn't by uttering the embedded sentence 'lying is immoral' that I assert a proposition about what is immoral relative to Albert's morality. Rather, it is by uttering the entire sentence, including the 'Albert believes that' operator.

So normal belief ascription contexts do not provide the context for which the Salience Relativist is looking.

However, imagine a context in which Bertrand asks you 'Does Albert believe that lying is moral or that lying is immoral?' Not wanting to waste your breath, you might respond by uttering

(S) Lying is immoral.

Call these sorts of contexts, in which a sentence occurs within the scope of an operator, even though it occurs in a different sentence from that in which the operator occurs, truncated contexts. Perhaps the Salience Relativist would say that these truncated contexts are the sort of contexts he had in mind.

But this really won't do at all. One does not assert the proposition expressed by a sentence when that sentence occurs within the scope of a belief operator, and in the above 
example of a truncated context, the utterance of (S) occurs within the scope of a belief operator. The fact that it was Bertrand instead of you who uttered the word 'believes' is simply irrelevant. And I confess that once truncated contexts are ruled out, I simply cannot think of any context in which it is intuitively plausible to suppose that, by uttering a moral sentence, a speaker asserts that something is moral or immoral relative to someone else's morality.

Now, given that we have yet to say anything about what makes a morality salient to a speaker, the Salience Relativist could say that it is always a speaker's own morality that is salient to him when he utters a moral sentence, and that this explains why there are no contexts in which a speaker asserts a proposition about what is moral or immoral relative to someone else's morality by uttering a moral sentence. But this would be unacceptably ad hoc. It would be analogous to someone trying to explain why one cannot utter the sentence 'I am twelve years old' and thereby assert a proposition about someone else's by age by saying that even though ' $I$ ' really refers to whomever happens to be salient to the speaker at the time of assertion, it is only used when the speaker is salient to himself.

3.4 So both forms of relativism are inconsistent with our intuitions about truth ascriptions, with our intuitions about the relations between sincere assertions of moral sentences and moral beliefs, and with our intuitions about when people's assertions of moral sentences are inconsistent. Moreover, Speaker Relativism is inconsistent with our intuitions about what third-person moral belief attributions are about. And Salience Relativism conflicts with our intuitions about whether it is possible to assert that something is moral or immoral relative to someone else's morality by uttering a moral sentence. In short, neither form of relativism fits well with other claims that we find independently plausible. 


\section{The First Two Strategies for Explaining Away our Linguistic Intuitions}

4.I Now, the Appraiser Relativist will undoubtedly reply that the intuitions described in the previous section are simply unreliable, and that they can be explained away on grounds that are consistent with Appraiser Relativism. I propose to look at three recent strategies for explaining away the relevant intuitions, one suggested by David Wong and two suggested by Gilbert Harman. Because Appraiser Relativists typically focus on the counterintuitive implications of their view regarding when moral assertions are consistent, the strategies address that implication directly; but I take it that the strategies would, if successful, also serve to explain away the other problematic intuitions.

4.2 Let us restrict our attention to moral sentences that do not, on their faces at least, contain any context sensitive terms such as indexicals or demonstratives. The first strategy begins by taking notice of the fact that even though both forms of relativism imply that assertions of sentences such as

(S) Lying is immoral.

and

$(\sim \mathrm{S})$ It is not the case that lying is immoral

need not always be inconsistent, they leave open the possibility that they sometimes are. The Appraiser Relativist might then be able to make it out that the range of contexts within which we normally practice moral discourse is such that an assertion of a moral sentence is almost always inconsistent with an assertion of its syntactic negation. And if this could be made out, then the Appraiser Relativist could claim that we mistakenly but understandably overgeneralize to the conclusion that it was simply impossible for an assertion of a moral sentence to be consistent with an assertion of its syntactic negation. Let us call this ifrategy. "Overgeneralization". 
Wong employs Overgeneralization as follows:

I will argue ... that what constitutes human fulfillment varies with different groups and societies, and that such variation results in different extensions for 'adequate moral system' as the term is used among different groups and societies. If this kind of variation exists, it is not difficult to explain why absolutists should fail to recognize it. Our conceptions of what constitutes human fulfillment are to a large extent shaped by our personal experience, observations of those around us, and what we are taught on the subject. Relatively few of us have been in the position of being pressed to confront an alien conception of human fulfillment and to understand it. (Italics added; Wong 1984, 79)

Wong's suggestion seems to be that whenever "what constitutes human fulfillment" is the same for two people, those two people will share the same morality, and hence, if one of those people asserts a moral sentence and the other asserts that sentence's syntactic negation, their assertions really will be inconsistent. Further, because we rarely encounter people for whom "what constitutes human fulfillment" is not the same as it is for us, it will rarely be the case that an assertion of a moral sentence will be consistent with an assertion of that sentence's syntactic negation. Thus, we can utilize Overgeneralization to explain why we mistakenly think that it is impossible for any assertion of a moral sentence to be consistent with any assertion of that sentence's syntactic negation.

But Wong's attempt to utilize Overgeneralization fails, and the reason why it fails is that the disagreements in need of explanation are quite common and widespread. Wong cites disagreements about abortion (Wong 1984, 190 - 197) and disagreements about welfare, taxes, and property rights (Wong 1984, 146- I53). Harman also cites those disagreements, and adds to the list issues about the moral status of animals, euthanasia, and our duties to aid others (Harman and Thomson 1996, 10 - II). As Harman rightly recognizes, but as Wong seems to ignore, intractable disagreements over these matters occur not only between different societies, but within a single society, and even within a single family (Harman and Thomson 1996, 10). So it is not even remotely plausible to suggest both that what underlies thesic disagreements is that the parties to the 
disagreements have different moralities and that people rarely encounter someone with a morality other than their own.

Wong and Harman clearly think that much of the evidence for Appraiser Relativism comes from its ability to explain the intractability of the disagreements just mentioned. But what if an Appraiser Relativist were willing to forego this support for his theory, say, by restricting his relativistic explanation to disagreements that arise between cultures that have very little contact with one another?

I do not think that narrowing the range of disagreements will help the Appraiser Relativist. Even if it were rare for an assertion of a moral sentence to be consistent with an assertion of that sentence's syntactic negation, our linguistic intuitions would nonetheless reflect these rare cases, and we would not be tempted to overgeneralize. Consider the sentence 'Dogs dogs fight fight.' Upon canvassing the possible contexts in which that sentence might be used, many people find it intuitively obvious that there are no contexts in which that sentence is syntactically acceptable. But once you point out a context in which the speaker is using that sentence to say that dogs that dogs fight, also fight, the intuition goes away. Or, consider a more germane example: upon canvassing the possible contexts in which one person asserts 'Mother Theresa is a good person' and another person asserts 'It is not the case that Mother Theresa is a good person', it may seem as if those assertions are inconsistent in any possible context. But once you point out a context in which the first person is discussing who is a good person for helping the poor and sick, and the second person is discussing who is a good person to recruit for a professional basketball team, the intuition goes away.

In general, an intuition that something is impossible is much more sensitive to counterexamples than it is to confirming instances; so we should expect the particular intuition that it is impossible for an assertion of a moral sentence to be consistent with an assertion of that sentence's syntactic negation to he much more sensitive (t) counterexamples than to contirming instances. So even if the Appraiser Relativist were to 
claim that it was only in rare contexts that an assertion of a moral sentence was consistent with an assertion of that sentence's syntactic negation, I think that the linguistic intuitions of those who were aware of such contexts would nonetheless be sensitive to those contexts. Such people would therefore not be tempted to Overgeneralize. But it can hardly be denied that many people who are aware of such contexts nonetheless find the Appraiser Relativist's claim about consistency counterintuitive.

4.3 The second strategy for explaining away our linguistic intuitions is suggested by Harman when he appeals to an analogy from physics involving the relativity of mass (Harman and Thomson 1996, 13). Someone who had the concept of mass but who was not familiar with the theory of relativity would almost certainly be under the false impression that any assertion of a sentence of the form ' $\mathrm{X}$ has a mass of 100 grams' is inconsistent with any assertion of a sentence of the form 'It is not the case that $\mathrm{X}$ has a mass of roo grams'. But Harman tells us that we now know, thanks to Einstein, that "an object can have one mass in relation to one [spatio-temporal] framework and a different mass in relation to another" (Harman and Thomson 1996,3 ). So Harman could say that whatever it is that explains why our intuitions are unreliable in the mass case is also what explains why our intuitions are unreliable in the moral case. Let us call this strategy "Mass."

But what is it that explains why our intuitions are unreliable in the mass case? Harman does not tell us. It seems to me that the reason why a person who had the concept of mass might nonetheless persist in believing that mass is not relative is that the variation in mass between one spatio-temporal framework and another is only detectable (given the accuracy and precision of normal measuring instruments) if those spatio-temporal frameworks are moving at a relative speed approaching the speed of light. But as Einstein himself noted in 1920: "the changes in energy. ... to which we can 
subject a system are not large enough to make themselves perceptible as a change in the inertial mass of the system" (Einstein $196 \mathrm{r}, 47$ ). So no matter which spatio-temporal framework a person takes a mass measurement relative to, he always seems to get exactly the same result. We can therefore explain why people's intuitions are unreliable in the mass case by appealing to the fact that it is easy to conflate two mass measurements that are, by normal means, indiscernible.

If we think of people who engage in moral discussions as attempting to "measure the moral qualities" of something (e.g., the person engaging in a discussion about abortion can be thought of as attempting to measure the heinousness or permissibility of abortion), then Mass would say that our intuitions are unreliable in the moral case because the moralities relative to which people normally measure the moral qualities of a thing always yield moral qualities that are, by normal means, indiscernible, and so, people are unaware that there is any relativity involved.

But once spelled out, Mass clearly fails. It certainly is not the case that the moralities relative to which people normally measure moral qualities all yield moral qualities that are indiscernible. Who could persistently conflate the moral permissibility attributed to most abortions by pro-choicers with the moral heinousness attributed to those same abortions by pro-lifers?

\section{A Test for Determining the Reliability of our Linguistic Intuitions}

5.I Before turning to the third strategy for explaining away our intuitions, I think it will pay to see that both Mass and Overgeneralization make implicit use of a test for determining the reliability of our intuitions.

To state the test in a general form, let us adopt the following terminology. Let us say that a sentence is incomplete if and only if it expresses a proposition to the effect that an w-place relation holds, even though the sentence itself contains fewer than $n$ reterriris 
expressions. ${ }^{8}$ And when an incomplete sentence is uttered, let us call the object that is not explicitly mentioned in the sentence, but that nonetheless figures in the proposition asserted, the completing relatum. So sentences of the form 'The mass of $\mathrm{X}$ is $\mathrm{M}$ ' are incomplete because they express propositions to the effect that a three-place relation holds between an object (referred to by ' $\mathrm{X}$ '), a measure (referred to by ' $M$ '), and a spatio-temporal framework, and the spatio-temporal framework is the completing relatum. And sentences of the form ' $\mathrm{X}$ is taller' are incomplete because they express propositions to the effect that a two-place relation holds between one object (referred to by ' $\mathrm{X}$ ') and some other object, and this other object is the completing relatum. According to Appraiser Relativism, then, moral sentences such as

(S) Lying is immoral

are incomplete, and a morality is the completing relatum.

We can now state the test:

Test: The probability that a person's intuitions will be reliable about the logical relations between assertions of incomplete sentences and their syntactic negations is proportional to the probability that he or she is aware of the fact that what is being measured varies relative to different completing relata.

\subsection{It seems to me that Wong's strategy, Overgeneralization, and Harman's first} strategy, Mass, are best understood as implicitly relying on Test. Wong can be viewed as arguing that because people usually only have contact with their own morality, it is highly probable that people will be unaware of the fact that the measurements of moral qualities given by different moralities vary. And Harman can be viewed as arguing that because the moral qualities yielded by the various moralities are indiscernible from one another, it is

'This usctul rerminology is from (Harman 1978), (Thomson 1992a) and from Thomson's respimse .". Harman in (Harman and Thomson 1996). 
highly probable that people will be unaware of the fact that the measurements of moral qualities given by different moralities vary. Applying Test to the (mistaken) claim that it is highly probable that people will be unaware of the variation yields Harman and Wong's desired conclusion, that it is highly probable that people's intuitions will be unreliable.

So Harman and Wong are implicitly committed to Test; I think we should be committed to Test as well. Test seems intuitively plausible, and it gives the correct answer about the cases we have discussed so far. Obviously, it is highly probable that every competent speaker of English will be aware of the fact that relative to different objects, one and the same thing can be shorter than some and taller than others. So Test yields the intuitively correct conclusion that it is highly probable that the intuitions of every competent speaker of English will be reliable in the '... is taller' case. And obviously, it is highly probable that someone who is not acquainted with Einstein's theory of relativity will be unaware of the fact that relative to different spatio-temporal frameworks, one and the same thing can have different masses. So Test yields the correct conclusion that it is highly probable that such a person will have unreliable intuitions in the mass case. But it is highly probable that someone who is well-versed in Einstein's theory of relativity will be aware of the fact that relative to different spatio-temporal frameworks, one and the same thing can have different masses. Therefore, Test yields the conclusion that it is highly probable that the relevant intuitions of such a person are reliable. And this also seems correct.

In Section 7, I will apply Test to the moral case, and argue that it yields the opposite of what the Appraiser Relativist needs it to yield. But we need to first look at a third strategy for explaining away our linguistic intuitions, for if that strategy works, it provides a counterexample to Test. 


\section{The Third Strategy for Explaining Away our Linguistic Intuitions}

6.I The third strategy for explaining away our linguistic intuitions is suggested by

Harman when he asks us to consider "the ancient question [of] whether the earth moves or the sun moves" (Harman and Thomson 1996, 12). How are we to explain the intractability of the disagreement that this question generated? Harman tells us the following:

Here the relativistic answer is correct. Motion is a relative matter. Something can be in motion relative to one system of spatio-temporal coordinates and not in motion relative to another. The particular motion an object exhibits will differ from one system to another. There is no such thing as absolute motion, apart from one or another system of coordinates. (12-13)

I take it that Harman is suggesting that the different parties to the ancient disagreement had different spatio-temporal frameworks in mind. This allowed both parties to speak truly and so neither could refute the other. But it took many centuries for the debate to finally be resolved, so they obviously didn't realize that they were talking past one other. And Harman tells us that an analogous explanation "is also plausible in the moral case" (13). So Harman could say that whatever it is that explains why our intuitions are unreliable in the motion case also explains why our intuitions are unreliable in the mord case. Let us call this strategy "Motion".

It is worth noting that neither Overgeneralization nor Mass will explain why the ancient disagreement was so intractable. Overgeneralization will not work becalse it is often the case that people determine whether something is in motion relative to many different spatio-temporal frameworks, sometimes relative to the earth, sometimes relative to this or that moving vehicle. And Mass will not work because relative to those different frameworks, we get easily noticeable differences in relative speed.

It is also worth noting that if Harman is right that what explains the why the ancient disagreement was so intractable is that both parties to that disagreement were speaking truly while mistakenly believing their assertions to be inconsistent, then we have a counterexample to Test. For precisely those reasons that make Overgeneralization and 
Mass fail in the motion case, it seems that pecple should be aware of the fact that relative to different spatio-temporal frameworks, one and the same object can exhibit different motions. Test then implies that people should not believe their assertions are inconsistent when they are not.

\subsection{But it seems plain that Harman is mistaken, both in his characterization of the} disagreement as being one in which both parties were speaking truly, and as to what explains why it took su long for the disagreement to be resolved. After all, modern astronomy teaches us that the disagreement was eventually resolved in favor of those who asserted 'The earth is revolving around the sun' (or some translation thereof), and it is, after all, obvious that motion is relative. It does not take any sophisticated equipment or subtle experiments to realize that the propositions asserted in the following two contexts are consistent. In the first context, the speaker is on a train, and upon observing that his children have stopped racing up and down the aisles, he asserts the sentence "The children are stationary.' In the second context, a speaker is on the platform and says of the same train 'That train, and the children on it, are moving'.'

But if people's linguistic intuitions are reliable in the motion case, then Motion fails. Harman cannot say that what explains the unreliability of our intuitions in the moral case is the same thing as what explains the unreliability of our intuitions in the motion case if, as I have argued, our intuitions are not unreliable in the motion case.

6.3 The question remains, though, how do we characterize the ancient disagreement, and why did it take so long to be resolved? Well, obviously this will require some

\footnotetext{
"The idea that motion is relative is even granted by these such as Newton who believed in absolute yaic. Newton says that "motion and rest, as commonly conccived, are only relatively distinguished" (. Newton 1966, 2). Absolute motion is simply motion, "as commonly conccived," relative to absolute space (.Nikinn 1966, 7).
} 
speculation, and given that the disagreement persisted for so long and that there were so many different parties to it, it seems unlikely that there will be any single explanation that applies across the board. Nevertheless, the following story seems plausible.

One reason why Aristotle would have asserted (a translation of) The earth is stationary' is because he was aware of the fact that there was no discernible stellar parallax (Abell 1982, 18). ${ }^{10}$ Parallax is the degree of shift in the apparent position of an object as a result of the object's motion relative to an observer, and stellar parallax is the degree of shift in the apparent position of a star as a result of the earth's motion relative to that star. To illustrate a simple case of parallax, imagine that you put this paper down at a distance of two feet directly in front of you, and then move two feet to one side. The parallax between the apparent position of the paper when it was directly in front of you and after you moved two feet to one side would be forty-five degrees. If you were to place the paper down at a distance of four feet directly in front of you, and then move two feet to one side, the parallax would be twenty-two and one-half degrees. The farther the paper is from you, the smaller the parallax, and the more it will seem to you as if you have not moved relative to the paper.

Now, Aristotle reasoned that if the earth revolved around the sun, then there would be a stellar parallax between the apparent position of the stars when the earth was on one side of the sun and the apparent position of the stars when the earth was on the other side of the sun. However, because the stars are so far away, Aristotle's contemporaries could not discern any stellar parallax. Aristotle was aware of this fact, and so he asserted 'The earth is stationary'. Knowing that the sun and the earth were in motion relative to each other, Aristotle then asserted 'The sun revolves around the earth'.

Now, a measure of stellar parallax is a measure of a relation between an observer and a star, and so it seems reasonable to speculate that when Aristotle asserted 'The earth is

\footnotetext{
"See $296 \mathrm{~b}$ of On she Heasiens.
} 
stationary' and 'The sun revolves around the earth', he was implicitly taking the stars against which he was measuring the stellar parallax as defining his reference frame. That the earth was stationary with respect to the stars and that the sun was in motion with respect to the stars was a perfectly reasonable view for Aristotle to have held, given that the stellar parallax was indiscernible. Indeed, even with the improved instruments of the sixteenth century, Tycho Brahe was still unable to detect any stellar parallax, and used this fact as an argument against those who asserted 'The earth is moving'. While Brahe acknowledged that the stellar parallax would be undetectable if the stars were very far away, astronomers still thought of the stars as lying just outside of Saturn. At such a close distance, stellar parallax would have been discernible with Brahe's instruments (Hoskins 1997a, III).

In the eighteenth century, astronomers determined by other methods that some stars were at least four-hundred-thousand times as far away from the earth as the earth is from the sun, and in the nineteenth century, stellar parallax was finally detected by Wilhelm Struve, and then by Friedrich Bessel (Hoskins 1997b, 219). Thus, Aristotle's view has been shown to be false.

However, as early as the seventeenth century, astronomers were beginning to understand that the motions of the sun and the earth were explained by gravitational forces, and so it became common to take the more massive sun as defining their reference frame (Hoskins I997b, 210). And modern astronomers do roughly the same thing: they take the center of mass of the earth-sun system as defining their reference frame because it is towards this center of mass that both the earth and the sun are constantly accelerating as they orbit about each other. George Abell, for example, says that becausc the mass of the sun is approximately 300,000 times the mass of the earth,

the common center of mass of the earth-sun system must be less than $\mathrm{x} / 300,000$ of the distance from the center of the sun to the center of the earth. This puts it well 
inside the surface of the sun. Essentially, then, the earth revolves around the sun. (Abell 1982, 109)"

This story seems quite plausible, but it stands in stark contrast with the story that Harman would have us accept about intractable moral disagreements. Harman would have us accept that what explains the intractable moral disagreements we see is that the parties to it are both speaking truly, but it is wrong to say that both parties to the ancient disagreement about the earth and the sun spoke truly. Scientific investigation has shown that the ancients who asserted The sun revolves around the earth' spoke falsely. And what explains why it took so long to show that they spoke falsely is simply that it took that long to develop sufficiently precise instruments and a better understanding of the gravitational forces underlying celestial mechanics. But surely Harman doesn't want to suggest that intractable moral disagreements are going to be resolved by future scientific investigation and technological innovation.

6.4 In summary, the three strategies for explaining away our intuitions regarding the logical relations between assertions of moral sentences do not succeed.

Overgeneralization fails because the disagreements in need of explanation are common and widespread. Mass fails because the moralities relative to which people normally measure the moral qualities of something yield moral qualities that are easily discernible. And Motion fails because it simply isn't true that our intuitions are unreliable about the logical relations between assertions of sentences about motion.

"It is also interesting to note that the center of mass of the earth-moon system is inside the tarth's surface (Feynman 1995, 99), so we can understand why an assertion of "Essentially, then, the moon revolves around the carth" is true if we take the completing relatum to be the reference frame given by the center of mass of the earth-moon system. 


\section{Appraiser Relativism, Explanation, and the Reliability of our Linguistic Intuitions}

7.1 In Section 3, we examined how well the truth of Appraiser Relativism would fit in with other claims that we find independently plausible. I now want to turn to the question of how well the truth of Appraiser Relativism would explain the moral disagreements it purports to explain.

7.2 Once Test has been explicitly spelled out, it seems quite plausible to think that if either form of Appraiser Relativism were true and moral sentences really were incomplete, Test would yield the conclusion that it is highly probable that people's intuitions will be reliable about the logical relations between the assertions of moral sentences. Contrary to Wong's suggestion, most people have had contact with many different moralities. And contrary to Harman's suggestion, the different moralities with which people normally have contact yield dramatically different moral qualities for one and the same action. But if these moral qualities differ dramatically from one another, then surely people would notice these dramatic differences as soon as they encountered these different moralities. To maintain otherwise would be akin to saying that an astronaut who has made multiple trips to the moon was unaware of the fact that the weight of an object varies with respect to different gravitational fields. It is possible, but highly unlikely.

So if Appraiser Relativism were true, then it would be highly probable that people would be aware of the fact that the moral qualities of something vary relative to different moralities. Test, then, yields that if Appraiser Relativism were true, it would be highly probable that people's intuitions would be reliable about when parties to a moral disagreement were really contradicting one another.

Recall now that Appraiser Relativism's explanation of the apparent intractability of moral disagreements about capital punishment, abortion, euthanasia, and so on, hinged 
on the fact that the parties to those disagreements persisted in mistakenly believing that their assertions were inconsistent. This is what provided the impetus to insist on refuting the opposing party's assertion, which could not be done because the assertion of the opposing party was true. But if, as I have argued, Appraiser Relativism implies that it is highly probable that people's intuitions will be reliable about when their assertions are inconsistent, then if Appraiser Relativism is true, it is highly improbable that people will persist in believing that their assertions are inconsistent when they aren't. And, once aware of the consistency of the assertions, they will no longer view the refutation of their opponent's view as a prerequisite for establishing their own. They would satisfy themselves with establishing the truth of their own assertion, and then turn to the quite different question: given that both of their assertions are true, what ought they to do?

In short, if Appraiser Relativism were true, then the very intractability that is in need of explanation will turn out to be highly improbable.

7.3 Now, it is of course a difficult question exactly when the truth of one proposition would provide an explanation of the truth of another, and $\mathrm{I}$ offer nothing that approaches a set of necessary and sufficient conditions. However, the following necessary condition seems roughly correct:

Explanation: If the truth of an explanans (Es) would make it highly improbable that an explanandum (Ed) is true, then the truth of (Es) would not explain the truth of (Ed).

To motivate Explanation, imagine the following case. Suppose that Albert knew that he weighed I50 pounds, but that he lied to his friend by saying that he weighed I30 pounds. We might then wonder what explains the following explanandum:

(E) Albert lied to his friend by saying that he weighed 130 pounds. 
Now, there are many propositions the truth of which would provide an explanation of (E), although some of the explanations might not be particularly good. Consider

( $\mathrm{P}_{\mathrm{I}}$ ) Albert is vain.

Intuitively, $\left(\mathrm{PI}_{\mathrm{I}}\right.$ ) would provide an explanation of $(\mathrm{E})$. However, it might come to light that while $(\mathrm{Pr})$ would provide an explanation of $(\mathrm{E})$, it would not provide a very good explanation of (E). This might be because, say, 150 pounds is closer to an attractive weight for someone of Albert's height than is 130 pounds. Thus, it might turn out that

$\left(P_{2}\right)$ Albert had a bet with his friend that he would win if, but only if, he weighed 130 pounds

would provide a better explanation of $(E)$ than would $\left(\mathrm{PI}_{\mathrm{I}}\right)$. But either $\left(\mathrm{PI}_{\mathrm{I}}\right)$ or $\left(\mathrm{P}_{2}\right)$ would provide an explanation of (E), even if the explanation provided wouldn't be a particularly good one.

But contrast $\left(\mathrm{PI}_{\mathbf{1}}\right)$ and $\left(\mathrm{P}_{2}\right)$ with

$\left(\mathrm{P}_{3}\right) \quad$ In all the years they have known each other, Albert has never lied to his friend.

Intuitively, $\left(\mathrm{P}_{3}\right)$ would not explain (E). Not only would it not provide a good explanation of (E), not only would it not provide a bad explanation of (E), it would not provide any explanation of $(E)$ whatsoever. And it seems plausible to suppose that the reason why it doesn't provide any explanation whatsoever is that the truth of $\left(\mathrm{P}_{3}\right)$ would make $(\mathrm{E})$ highly improbable.

7.4 Recall now that I had argued that if Appraiser Relativism were true, then the very intractability in need of explanation would turn out to be highly improbable. Explanation, then, yields that the truth of Appraiser Relativism would not provide any explanation 
whatsoever of this intractability of the relevant disagreemcrnts. A fortiori, even if we were to grant that Appraiser Relativism were true, its truth would not provide the best explanation of the intractability of the relevant disagreements, and the argument for Appraiser Relativism on the ground that it would is unsound.

\section{Summary and Concluding Remarks}

8.I In summary, I have argued that neither Speaker Relativism nor Salience Relativism can be supported by claiming that it provides the best explanation of the intractable moral disagreements we see surrounding capital punishment, abortion, euthanasia, and other fundamental moral issues. After detailing a number of intuitions with which they conflict, I examined three arguments for the conclusion that those intuitions were unreliable, and so could not serve as evidence against Appraiser Relativism. This examination yielded two conclusions. First, that the arguments are unsound. Overgeneralization fails because the disagreements that the Appraiser Relativist hopes to explain are common and widespread. Mass fails because it is not the case that the moral assessment yielded by different moralities are indiscernible. And Motion fails because our intuitions in the motion case are reliable. The second conclusion was that Test seems to be a good guide to judging the reliability of our intuitions.

Third, I argued that Appraiser Relativism does not provide the best explanation of the relevant disagreements. Appealing to Test, I argued that if Appraiser Relativism were true, it would be highly probable that people's intuitions about when they were disagreeing would be reliable. So if the parties to a moral disagreement really were talking past one another, as the Appraiser Relativist supposes, the parties would realize that that they were. They would then give up trying to refute the other person, and the disagreement would be resolved. Thus, if Appraiser Relativism were true, then the very disagreements in need of explanation will turn out to be highly improbable. Then Explanation implies that Appraiser Relativism does not provide any explanation of those 
disagreements. A fortiori, Appraiser Relativism does not provide the best explanation of those disagreements, and the argument for Appraiser Relativism on the ground that it does is unsound.

8.2 Of course, this leaves us with the question of what is the best explanation of the intractable disagreements we often see surrounding fundamental moral issues. This is a large question, and one to which I have no general answer. Nevertheless, a few observations are in order.

First, I think it is doubtful that there is a single explanation that applies to all of the relevant moral disagreements. Part of the explanation of why disagreements about capital punishment are intractable is that we do not at present have an adequate theory of retributive justice; but our lack of an adequate theory of retributive justice plays no role in explaining the intractability of disagreements about abortion. Further, part of the explanation of why disagreements about abortion are intractable is that we lack an adequate theory of personhood; but this lack obviously plays no role in the explanation of explaining the intractability of disagreements about capital punishment. (No one seriously doubts that people on death row are people.) In short, one should not expect the disagreements of applied ethics to be resolved until the relevant underlying theoretical disagreements are resolved, and what these underlying theoretical disagreements are will vary from disagreement to disagreement.

Second, even in the absence of any positive explanation of why moral disagreements tend to be intractable, if the arguments I have given in this chapter are sound, we know that both Speaker Relativism and Salience Relativism can be ruled out of court.

8.3 And finally, it should he noted that many of the considerations brought forth in this paper hear not only on the soundness of the argument for Appraiser Relativism, but 
also on the plausibility of Appraiser Relativism itself. Any philosophical theory that runs counter to our pre-theoretical intuitions comes at a cost. If those intuitions cannot be explained away, the cost is even greater. And if those intuitions are as firm and as widely held as the intuitions which run counter to Appraiser Relativism are, then I think the cost is very high indeed. 



\section{Chapter Two \\ Agent Relativism and Reasons for Action}

\section{The Practicality Argument}

I.I Let us define Moral Universalism as the thesis that there is at least one universal moral requirement. This can be stated more precisely: there is at least one kind of action such that morality requires every agent to refrain from performing any action of that kind. ${ }^{12}$ Precision being in tension with readability, however, I am going to adopt two clutter-reducing assumptions. First, I am going to assume that refraining from performing an action is itself performing an action. Second, I am going to dispense with talk of kinds of actions and speak instead just of actions, but I will do so while assuming that two different agents can perform the same action. We can now define Moral Universalism as follows:

Moral Universalism: There is some action such that every agent is morally required to perform that action.

I.2 I am inclined to think that Moral Universalism, so defined, is true. It has been argued, however, that reflection on the practical nature of morality and on the nature of reasons for action reveals that Moral Universalism isn't true, and that we should instead accept its negation, which I will call Agent Relativism. ${ }^{13}$ According to Agent Relativism there are no universal moral requirements. That is:

$\therefore$ In apent is someone who is subject to some moral requirements.

"A "Apent Relativism" contrasts with "Appraiser Relativism", which was the subject of Chapter One. Wherew Appraiser Relativism addresses itself to features of the agent who is appraising the action in

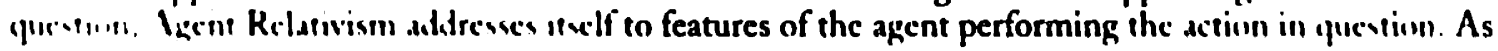


Agent Relativism: For any action, there is some agent who is not morally required to perform that action.

The argument I have in mind begins with the claim that reflection on the practical nature of morality reveals that if an agent is morally required to perform an action, then there is a reason for that agent to perform that action. Call this the Practicality Requirement:

The Practicality Requirement: For any action, if an agent is morally required to perform that action, then there is a reason for that agent to perform that action.

Next, it is argued that reflection on the way in which reasons for action are based on desires reveals that for any action, there is an agent such that there is no reason for that agent to perform that action. Call this Reasons Relativism:

Reasons Relativism: For any action, there is some agent such that there is no reason for that agent to perform that action.

And Reasons Relativism and the Practicality Requirement entail Agent Relativism. If there were some action such that every agent is morally required to perform that action, then it would follow from the Practicality Requirement that there is some action such that for every agent, there is a reason for that agent to perform that action. But this is precisely what Reasons Relativism denies.

1.3 Let us call this argument for Agent Relativism, the Practicality Argument. Anyone who is attracted to Agent Universalism needs a response to the Practicality Argument. I will argue that the Practicality Requirement is very plausible, and that Reasons Relativism should be rejected instead. Although I have no outright argument

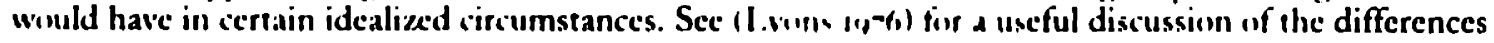
lecwern the two furms of relativion. 
that Reasons Relativism is false, I examine two arguments on its behalf, and conclude that they cannot be successfully used against the Moral Universalist. In the absence of further arguments, the Moral Universalist is therefore free to reject the Practicality Argument for Agent Relativism.

\section{Two Argument for Moral Universalism}

2.I Before turning to the Practicality Argument, however, let me address a prior question: why should anyone be attracted to Moral Universalism in the first place? There are two arguments sometimes put forward in its favor, one more persuasive than the other.

The first argument I will call the Argument from Extreme Heinousness. According to the Argument from Extreme Heinousness, some actions are simply so heinous that they could not possibly be morally permitted. Torturing a baby to death for fun is the standard example. But some people think that for any action alleged to be sufficiently heinous, they can conceive of possible circumstances where an agent is forced to choose between performing that action on one person and performing the same action on some absurdly large number of people. In such circumstances, these people say, the consequences of not performing the action in question are themselves so tragic that morality permits, perhaps even requires, that the agent perform the action. If you think, as I do, that numbers can matter, then you are unlikely to be persuaded by the Argument from Extreme Heinousness.

2.2 But there is another argument for Moral Universalism that I find more persuasive. This argument begins with the very modest claim that some agent is morally required to perform some action. Now, eithir all other agents are morally required to perform that action as well, or they are not. If they are, then the requirement is universal, and Moral Universalism w true. But if they are not, then there must be some morally relevant 
difference between the circumstances of those who are required and the circumstances of those who are not required. But then we can construct a more qualified moral requirement that takes this difference into account, and which, in conjunction with the difference in circumstances, explains the difference in moral requirements. That someone thinks morality exhibits this kind of "relativity to circumstances," as it is sometimes called, does not of course mark him as a Agent Relativist, but the strategy seems to be perfectly general: whatever differences exist between people who are subject to different moral requirements, once these differences have been noted as being morally relevant, a more qualified moral requirement can then be constructed which is such that everyone is subject to it. The relevant features of the circumstances are "built-in," so to speak, to the moral requirement. Call this argument the Argument from Morally Relevant Differences.

Unlike the Argument from Extreme Heinousness, the Argument from Morally Relevant Differences does not require that universal moral requirements be universal because the acts they prohibit are particularly heinous. For example, violating the suitably qualified moral requirement to keep one's promises, say, is not particularly heinous; there are worse things one could do. Nonetheless, because the requirement takes into account all those circumstances in which one is permitted to break one's promise, violating it is never morally permitted.

\subsection{Gilbert Harrnan, however, says that the Argument from Morally Relevant}

Differences is invalid. He says that it is possible for two people to be subject to different moral requirements, even though there is no more qualified moral requirement that applies to them both (Harman 1978). Rather, he says, it might be that the reason why the people are subject to different moral requirements is because of the truth of a general metaethical principle that places constraints on what morality requires. So, for example, many people have thought it a plausible metacthical prittciple that if an action is not 
within the power of an agent, then the agent is not morally required to perform that action. So if it turns out that Alfred promised to leap tall buildings, but doing so isn't within his power, then he is not morally required to keep his promise. But now, Harman says, it may turn out that Superman is morally required to leap a tall building, even though Alfred is not, and this difference in moral requirements would be explained by the truth of the general metaethical principle cited above, and the fact that Superman can, and Alfred cannot, leap tall buildings.

But Harman is mistaken in thinking that this sort of example sheds doubt either on Moral Universalism, or on the Argument from Morally Relevant Differences. If a morally relevant difference is any difference that makes a difference in what morality requires of agents (and what else could it be?), then the correct view to take is that there is a morally relevant difference between Superman and Alfred, viz., that Superman can leap tall buildings and Alfred cannot. This shows that the moral requirement to keep one's promises needs at least one qualification: one is morally required to keep only those promises that it is within one's power to keep. But it is unobjectionable to think that universal moral requirements can be suitably qualified to take into account such differences when and where they are relevant.

\section{A Defense of the Practicality Requirement}

3.1 So I think that Moral Universalism is true. But if Moral Universalism is true, then we need a response to the Practicality Argument, for its conclusion, Agent Relativism, is inconsistent with Moral Universalism. Recall that the Practicality Argument has two premises: the Practicality Requirement-which says that if morality requires an agent to perform an action, then there is a reason for that agent to perform that action-and Reasons Relativism, which says that for any action, there is some agent such that there is no reasion for that agent tio perform that action. So the first response to consider is one which denies the Practicality. Recquirement, and salys instead that it is possible for there (n) 
be no reason for someone to do that which morality requires. I will suggest, however, that on the proper understanding of the relationship between morality, reasons for action, and what an agent ought to do, denying the Practicality Requirement is implausible.

The Practicality Requirement says that if morality requires an agent to perform an action, there is a reason for that agent to perform that action. More briefly, there are always reasons to comply with one's moral requirements. But how are we to understand the term 'reason' as it appears in this premise? I intend to understand it as I think it is normally used. As the term 'reason' is normally used, a reason is a consideration in favor of an action. More precisely, a reason for an agent to do something is a consideration in favor of that agent's doing that thing. Reasons, in this sense, connect up with what an agent ought to do. When someone asks why he ought to do something, what he is asking for are the reasons there are for him to do that thing. He is asking for those considerations that are in favor of his doing that thing. So a reason for an agent to perform an action is a fact that is favorably relevant to its being the case that he ought to do that thing. ${ }^{14}$ Of course, there can be both reasons for an agent to do something and aiso reasons for that agent to not do that very same thing. When someone asks whether be ought to do something, what he is asking is whether the reasons there are for him to do it outweigh, are stronger than, or, as I shall put it, override the reasons there are for him not to do it. If they do, and only if they do, then the agent ought to perform the action.

3.2 On this understanding of reasons for action and what an agent ought to do, how troubled should we be about rejecting the Practicality Requirement and saying instead that it is possible for morality to require an agent to do something even though there is no reason for him to do it?

\footnotetext{
${ }^{14}$ Sece (Thomson Heyo, 1:-15)
} 
David Brink suggests that rejecting the Practicality Requirement shouldn't trouble us. Although he is optimistic about the prospects of demonstrating that there are always reasons for an agent to do what morality requires, he suggests that nothing is lost if we cannot always "reproach the immoralist" for doing what he ought not do, for we can still always "reproach the immoralist with immorality" (Brink 1997, 32). But you can hardly reproach the immoralist for acting contrary to morality if you think that the immoralist ought to be acting contrary to morality. Rather, Brink is committed to thinking that what it is correct to say about someone who has overriding reasons for acting contrary to morality is "I think you are doing exactly what you ought to be doing," which is hardly a reproach. So I think Brink is mistaken in his suggestion as to why it would be unproblematic to deny the Practicality Requirement. ${ }^{15}$

But I think there are two consequences of denying the Practicality Requirement that are troubling.

3.3 If the Practicality Requirement is false, then it is possible for morality to require an agent to do something even though there is no reason for him to do so. But if there is no reason for him to do so, then, a fortiori, the reasons there are for him to do so do not outweigh the reasons there are for him not to do so, and so it is not the case that he ought to do so. So if the Practicality Requirement is false, it is possible for morality to require an agent to do something even though it is not the case that he ought to do that thing. And that seems counterintuitive: most of us think that if morality requires you to do something, then you ought to do it.

\footnotetext{
"Bernard Williams makes the same mistake in his discussion of the criticisms that can be leveled against someone who cannot be convinced that he oughe to be nicer to his wife (Williams 1989, 39-40). Williams asks: what more do we need in sav ahour this person over and abowe saying that the person in question is inconsiderate, brutal, hard, ele: 'The answer is that we also want to say that the person oughe not he inconsiderate, houtal, hard, and so on. W'. want cur saving of these things wi) te criticisms, as they would not be in the mouth of someone who thought that one onght Io be inconsiderate, brutal, hard, and so on, inw.urds onc's wite.
} 
Some people, however, welcome this consequence. For example, Bernard Williams argues that while there are perhaps very strong reasons for people to comply with their moral requirements, those reasons are outweighed by other reasons in some circumstances. ${ }^{16} \mathrm{He}$ says

while we are sometimes guided by the notion that it would be the best of worlds in which morality were universally respected and all men were of a disposition to affirm it, we have in fact deep and persistent reasons to be grateful that that is not the world we have (Williams 1976, 23).

Before we can decide for or against a view such as Williams's, we would need to hear something about the sorts of reasons that are being claimed to override moral requirements. A full discussion would take us too far afield; suffice it to say that what I find puzzling about Williams's position is that it seems obvious to me that to the extent that these non-moral reasons do strike us as weighty enough to outweigh a moral requirement, they will also strike us as relieving us of the moral requirement with which they allegedly conflicted. Morality can, in unfortunate circumstances, require great personal sacrifice, but typically, morality itself makes room for other non-moral pursuits and values. And when it doesn't, I for one am inclined to think that what one ought to do is abide by one's moral requirements. Morality not only makes room for other non-moral pursuits and values, it makes the right amount of room for them. So, for this reason, I think it is troubling to think that morality can require someone to do something even though there is no reason for that person to do that thing.

3.4 There is also a second consequence of denying the Practicality Requirement, one that I think is more troubling than the first. A reason for an agent to perform an action is a fact that is favorably relevant to its being the case that he ought to perform that action.

\footnotetext{
in Similarly, Susan Wolf argues that moral considerations should not be the cxilusive ficcus of our concern, on the grounds that moral considerations would then be "apt to crowd cut the nonmonral virtues,

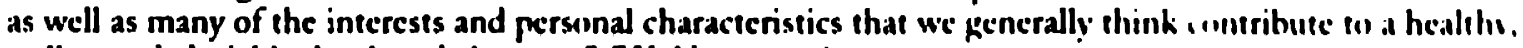
well-rounded, richly developed character" (WVilf $\left.11,8_{2},+21\right)$.
} 
So denying the Practicality Requirement requires saying that in some circumstances, even though it is a fact that morality requires an agent to do something, there are no facts that are favorably relevant to its being the case that he ought to do that thing; a fortiori, the fact that morality requires him to do that thing is itself not a fact that is favorably relevant to its being the case that he ought to do it. But how could that be possible? Surely the fact that morality requires an agent to do something is at least favorably relevant to its being the case that he ought to do it.

3.5 What would it take to convince us otherwise? We would have to come to believe a story about the source of morality, or about the source of some aspect of morality, and be convinced that anything coming from that source isn't worth caring about. A certain form of moral skepticism would have to be true, a form which Christine Korsgaard describes as follows:

The moral sceptic is someone who thinks that the explanation of moral concepts will be one that does not support the claims that morality makes on us. He thinks that once we see what is really behind morality, we won't care about it any more. (Korsgaard 1996, 13-14) $)^{17}$

For example, suppose Thrasymachus, of Plato's Republic, tried to convince us that his views about the source of morality were true. Roughly, according to his story, the rulers are enabled by their superior strength and motivated by self-interest to control the upbringing and education of their subjects, and they do so in such a way that their subjects grow up believing, first, that they ought to be just and, second, that being just requires compliance with whatever laws are made by the rulers. Further the laws in fact made by the rulers are crafted solely to serve the interests of the rulers at the expense of

\footnotetext{
${ }^{17}$ Korsgaard's description of the skeptic iv inaccurate, theugh. It may he that once we see what is

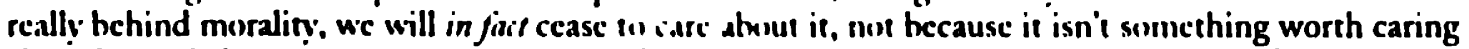
abrut but only because we dre somehow confiuced in mistaken aluoue the correct grounds for caring about something. What Korsgadrd should have said w that the skeptic thinks that once we sec what is really

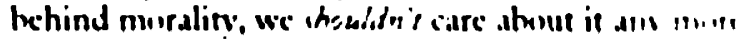


the interests of the subjects. Thrasymachus, being the enlightened person that he is, realizes this, and concludes that the subjects shouldn't be just. Indeed, Thrasymachus seems to think that the fact that something is just is a reason not to do it, because injustice is always "to one's own profit and advantage" (Book I, 344C). Thrasymachus, therefore, is an example of someone who rejects the Practicality Requirement.

But Thrasymachus had another option. He could have concluded that being just does not require compliance with the laws made by the rulers. And indeed, that seems right. Justice does not require subjects to abide by the law when the law is crafted solely to serve the interests of the rulers at the expense of the interests of the subjects. So I fail to be convinced by Thrasymachus's story, and I expect the point generalizes: whenever someone tries to tell a story that if true, would imply that a person ought not be just, then my response will be to reject his account of justice, not to reject the Practicality Requirement.

Intuition and ordinary usage also support the Practicality Requirement. We do talk as if moral requirements are reasons for action. If I say that you should pay back the five dollars you borrowed from Alfred and you ask why, it seems perfectly appropriate to say "Because morality requires you to do so." In saying that, I seem to have stated a reason why you ought to pay back the five dollars. However, trying to underwrite these intuitions with a theory has proven to be enormously difficult, and it is not something that I am in a position to do. ${ }^{18}$ Suffice it to say, though, that even in the absence of a theory to underwrite these intuitions, I think it would be morc plausible to give up Moral Universalism than to give up the Practicality Requirement. So I think that the defender of Moral Universalism would do well to focus his or her attention on Reasons Relativism, the other premise in the Practicality Argument for Agent Relativism.

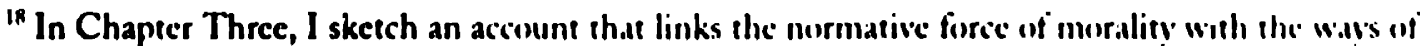
treing gond.
} 


\section{The Desire Argument for Reasons Relativism}

4.I Recall that Reasons Relativism says that for any action, there is some agent such that there is no reason for that agent to perform that action. I will look at two different arguments for Reasons Relativism. The feature these arguments share is that they both tie the reasons there are for an agent to do something to the desires the agent would have, in certain idealized circumstances. I will argue that neither of them can be successfully used against the Moral Universalist, and that a view of reasons for action according to which they are often not related to an agent's desires can be squared both with naturalistic scruples and with the correct account of the relationship between reasons for action and motivation.

The first argument for Reasons Relativism that I am going to examine goes as follows:

\section{The Desire Argument}

(Pr) There is a reason for an agent to perform an action if and only if the agent would, were he fully rational and fully informed, have some desire that would be served by his performing that action. ${ }^{19}$

$\left(\mathrm{P}_{2}\right)$ For any action, there is some agent who would, despite being fully rational and fully informed, have no desire that would be served by his performing that action.

(C) Hence, for any action, there is some agent such that there is no reason for that agent to perform that action.

Call this argument for Reasons Relativism, the Desire Argument. My response to the Desire Argument is in the form of a dilemma. The first horn of the dilemma focuses on the second premise of the Desire Argument, $\left(\mathrm{P}_{2}\right)$. The typical argument for $\left(\mathrm{P}_{2}\right)$ claims that, regarding the most plausible examples of actions which a Moral Universalist might claim to be morally required of every agent, it is possible for there to be an agent who (i) is fully informed, (ii) is fully rational, and yet (iii) has no desires that would be served by his complying with the allegedly universal moral requirement. For example, against the

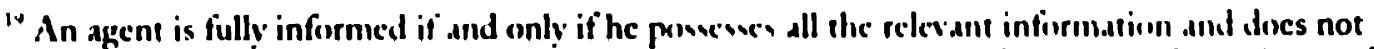
pressess any relevant misinformation, has drawn all the eclevent conclusums from that intiormution, and has

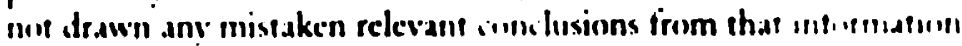


claim that every agent is morally required to refrain from killing innocent people, Gilbert Harman says that it is possible for there to be a fully rational, fully informed member of "Murder, Incorporated" who has no desires that would be served by his refraining from killing his innocent victims (Harman 1975). ${ }^{20}$

Let us suppose that the name of the member of Murder, Incorporated is named "Villain." Harman would have us believe that Villain is fully informed, fully rational, and yet lacks any desire of the relevant kind. But on the most natural understanding of "fully informed," according to which being informed means, among others things, being informed about reasons for action, then I think it can be shown that this description of Villain begs the question against the defender of Moral Universalism.

4.2 My argument that this description of Villain begs the question relies on a general principle, which I will call "Moral Internalism," that places constraints on the desires of fully informed, fully rational agents. The principle says if an agent (i) is fully informed, (ii) is morally required to perform some action, and yet (iii) has no desire that would be served by performing that action, then he is not fully rational.

The derivation of that principle goes as follows. Let Alfred be our representative agent and dancing be our representative action. Suppose that Alfred is fully informed, that morality requires Alfred to dance, and yet that Alfred has no desire that would be served by his dancing. If, as we are supposing, morality requires Alfred to dance, then it follows from the Practicality Requirement that there is a reason for Alfred to dance. But if, as we are supposing, Alfred is fully informed, then if there is a reason for him to dance, he believes that there is a reason for him to dance. So Alfred believes that there is a reason for him to dance.

\footnotetext{
${ }^{21}$ Of course, the parties to this debate are not really committed en thinking that not killing innurent perople really is a universal moral requirement; it just serves as a usefiul eximple.
} 
Now, the following modest form of internalism about reasons for action seems plausible:

Reasons Internalism: If an agent believes that there is a reason for him to perform an action, and yet is in no way motivated to perform that action, then the agent is not fully rational.

The question of what marks an agent as fully rational is, of course, a difficult one. But the idea that at the very least, full rationality requires that one be moved to some extent by what one takes to be reasons is very plausible. A fully rational agent cannot be left entirely cold by what he takes to be a reason. (I will return in a moment to what happens if we deny Reasons Internalism.)

Now, we saw that Alfred believes that there is a reason for him to dance. Since we are also supposing that he has no desire that would be served by his dancing, it then follows from Reasons Internalism that either (i) Alfred is motivated to some extent to dance despite the fact that he has no desire that would be served by his dancing, or (ii) Alfred is not fully rational.

The first option, that Alfred is motivated to some extent to dance despite the fact that he has no desire that would be served by his dancing, is ruled out if we accept the Humean Theory of Motivation, according to which all "motivation has its source in the presence of a relevant desire and means-end belief" (Smith 1994, 92). The Humean Theory can be spelled out more precisely as follows:

The Humean Theory of Motivation: An agent is motivated to perform an action if and only if he has some desire he believes would be served by his performing that action.

I think that the Humean Theory of Motivation is correct. ${ }^{21}$ If it is, then if Alfred is motivated to dance, he must have a desire that he believes would he served by his

\footnotetext{
"Sece (Smith 8994) firr a tull-fledged deprone
} 
dancing. Now, because Alfred is fully informed, he will not believe that he has a desire that would be served by his dancing unless he really does have such a desire. So if Alfred is motivated to dance, then he really does have a desire that would be served by his dancing. But we stipulated that he has no such desire. Hence, he is not motivated to dance, even though he believes there is a reason for him to dance. We are therefore forced to conclude that Alfred is not fully rational, for he is not motivated to do that which he believes there is a reason for him to do. In short, if Alfred is fully informed, and if morality requires Alfred to dance, and yet Alfred has no desire that would be served by his dancing, then Alfred is not fully rational. Generalizing, we have:

Moral Internalism: If an agent is fully informed, morally required to perform some action, and yet has no desire that would be served by his performing that action, then he is not fully rational.

4.3 Moral Internalism follows from the Practicality Requirement, Reasons Internalism, and the Humean Theory of Motivation. Within the context of the Practicality Argument, we can take the Practicality Requirement as given. Reasons Internalism and the Humean Theory of Motivation are then the only premises objectionable to someone who wanted to maintain the Practicality Argument. But these seem quite plausible.

With Moral Internalism in hand, let us return to Harman's argument against the claim that there was a universal moral requirement to refrain from killing innocent people. Harman claimed that Villain was fully informed, fully rational, and yet had no desire that would be served by refraining from killing his innocent victims. But if Villain really does not have any desire that would be served by his refraining from killing his innocent victims, then the Moral Universalist will respond to Harman's description of Villain by saying that Villain is either irrational in that his desires do not reflect his belicfs 
about what he has reason to do, or that he is uninformed of the fact that there is a reason for him to refrain from the killings. In either case, by the lights of the Moral Universalist, Villain fails to satisfy the conditions specified in the second premise of the Desire Argument, namely that the agent in question be fully informed, fully rational, and lack a desire of the relevant kind.

I should stress that I am not merely saying that my intuition that Villain is morally required to refrain from killing his victims is stronger than my intuition that Villain is fully rational and fully informed. That is, I am not merely rejecting Harman's argument because I disagree with its conclusion. Rather, my rejection is based on the fact that Moral Internalism is an independently plausible constraint that governs the desires of fully informed, fully rational agents, and that our belief as to whether Villain is fully rational or not will depend upon our prior beliefs about what he takes to be the reasons there are for him to act in certain ways. If Villain is stipulated to be fully informed, then our beliefs about whether he is fully rational will depend upon our prior beliefs about what reasons there really are for him to act in certain ways. In light of the Practicality Requirement, which links moral requirements with reasons for action, this means that our belief as to whether Villain is fully rational or not will depend upon our prior beliefs about what morality requires of him, and this is precisely what is at issue between the Moral Universalist and the Agent Relativist.

So any attempt to provide support for the second premise of the Desire Argument by way of such examples begs the question against the Moral Universalist. In the absence of any other arguments forthcoming, the Moral Universalist is therefore free to reject the second premise, and along with it, the Desire Argument.

4.4 The argument just given relied on the principle that I called Reasons Internalism, which says that if an agent is fully rational and helieves that there is a reasion for him to 
do that thing, then he will be motivated to some extent to do that thing. A fully rational agent cannot be left totally cold by what he takes to be a reason. If Reasons Internalism is false, then the argument just given against the second premise of the Desire Argument is unsound. But, and here is the second horn of the dilemma, if Reasons Internalism is false, then the first premise of the Desire Argument is false as well, and so again, the Moral Universalist is free to reject the Desire Argument.

The first premise of the Desire Argument says that there is a reason for an agent to do a thing if and only if that agent would, were he fully rational and fully informed, have a desire that would be served by his doing that thing. But if Reasons Internalism is false, then that premise is false too. If Reasons Internalism is false, then it is possible for a fully rational agent to believe that there is a reason for him to do something and yet to be in no way motivated to do that thing. The fact that he is left totally cold by what he takes to be a reason doesn't mark him as less than fully rational. But now consider Villain. Harman asked us to suppose that Villain was fully rational, fully informed, and yet had no desires that would be satisfied by his refraining from killing his innocent victims. If the first premise of the Desire Argument were true, it would then follow that there is no reason for Villain to refrain from the killings. But if Reasons Internalism is false, it does not follow that there is no reason for Villain to refrain from the killings, for it may be that there is such a reason, but that reason simply fails to motivate Villain. It leaves him entirely cold. And if he is not motivated in any way to refrain from the killings, then the Humean Theory of Motivation implies that Villain does not have any desire that he believes would be served by his refraining from the killings. Hence, either (i) Villain has no desire that would be served by his refraining from the killings, or (ii) he has such a desire, but doesn't believe that it would be served by his refraining from his killings. But if Villain is fully informed, and he has a desire that would be served by his refraining from the killings, he would believe that he had such a desire. So (i) is ruled out. Hence, (ii) 
Villain has no desire that would be served by his refraining from the killings, and the first premise of the Desire Argument is false.

4.5 So if Reasons Internalism is true, then the second premise of the Desire Argument begs the question against the Moral Universalist. And if Reasons Internalism is false, then the first premise of the Desire Argument is false. Either way, the Moral Universalist is free to reject the Desire Argument.

\section{The Narrow Desire Argument for Reasons Relativism}

5.I Can the Desire Argument be amended so as to avoid the objection from the previous section? I would like to consider an amended version of the Desire Argument, one that does not require that the agent be fully informed. Let us say that a fact is $a$ practical fact if it is a fact to the effect that there is a reason for a particular action or to the effect that there is a reason for an action in certain circumstances. Examples of practical facts include the following: any fact to the effect that there is a reason for Jones to rake the leaves; any fact to the effect that there is a reason for Jones to not rake the leaves; any fact to the effect that there is a reason for Jones to rake the leaves in those circumstances in which his not raking the leaves would hurt his lawn; and any fact to the effect that there is a reason for Jones to rake the leaves in those circumstances in which he would enjoy raking the leaves.

The amendment, then, is to require that the agent be fully informed of all and only the non-practical facts, and also to require that the agent have no beliefs about the practical facts. This yields the following argument for Reasons Relativism, which I will call the Narrow Desire Argument.

\section{The Narrow Desire Argument}

(Pr) There is a reason for an agent to perform an action if and only if the agent would, were he fiuly rational and fully informed of all and only the non- 
practical facts, have some desire that would be served by his performing the action.

$\left(\mathrm{P}_{2}\right)$ For any action, there is some agent who would, were he fully rational and fully informed of all and only the non-practical facts, have no desire that would be served by his performing the action.

(C) Hence, for any action, there is some agent such that there is no reason for the agent to do that action.

I call this argument the Narrow Desire Argument, because the class of beliefs it counts as relevant is narrower than those counted as relevant in the first Desire Argument.

5.2 What reason is there for adopting the account of reasons for action expressed by (P.) of the Narrow Desire Argument? It has a number of aspects that need to be justified. First, what reason is there for excluding beliefs about the practical facts from our account of reasons for action? After all, the picture of a rational deliberator as canvassing what one takes to be the reasons for and against various courses of actions, and forming desires and intentions in accordance with those reasons, is very natural and attractive. But I think a relativist such as Harman would say that this picture misunderstands the reductive nature of his project. Harman is trying to give a naturalistically acceptable account of reasons for action, and he thinks that the only way to accomplish this is to reduce facts about reasons for action to facts about the desires one would have if one were fully rational and fully informed of all and only the non-practical facts. We exclude beliefs about the practical facts because our desires are supposed to be the source of our reasons, not the other way around.

That explains why the account of reasons for action expressed by $\left(\mathrm{PI}_{\mathrm{I}}\right)$ excludes beliefs about the practical facts, but the account of reasons for action has other features as well that are still in need of justification. The account of reasons for action expressed by $\left(\mathrm{P}_{\mathrm{I}}\right)$ is both agent-centered and desire-based. It is agent-centered in that it says that an agent's reasons for action are a function only of facts about himself, and it is desire-based because it says that the relevant facts about the agent are facts about his own desires. So why 
exactly does Harman think that naturalistic scruples commit us to an agent-centered, desire-based view of reasons for action? Harman says the following:

Consider what it is for someone to have a sufficient reason to do something. Naturalism requires that this should be explained in terms congenial to science. Wc cannot simply treat this as irreducibly normative, saying, for example, that someone has a sufficient reason to do something if and only if he or she ought to do it. Now, presumably, someone has a sufficient reason to do something if and only if there is warranted reasoning that person could do which would lead him or her to decide to do that thing. A naturalist will suppose that a person with a sufficient reason to do something might fail to reason in this way to such a decision only because of some sort of empirically discoverable failure, due to inattention, or lack of time, or failure to consider or appreciate certain arguments, or ignorance of certain available evidence, or an error in reasoning, or some sort of irrationality or unreasonableness, or weakness of will. If the person does not intend to do something and that is not because he or she has failed in some such empirically discoverable way to reason to a decision to do that thing, then, according to the naturalist, that person cannot have a sufficient reason to do that thing. (Harman 1984, 372)

Two different arguments are at work in this passage, and they need to be distinguished.

5.3 First, there is an argument that naturalistic scruples require that we analyze reasons for action in terms that are acceptable from a naturalistic perspective. Harman says that we cannot simply treat someone's having a sufficient reason to do something as irreducibly normative, and he says that this rules out our merely saying that somcone has a sufficient reason to do something if and only if he or she ought to do it. The term on the right hand side, "ought to do it," itself needs to be explained from a naturalistic perspective. I agree with Harman that we should not accept this as an analysis of reasons for action. But this does not require accepting an agent-centered, desirc-based theory of reasons. After all, consider a theory of reasons for action similar to the one adopted by Thomas Nagel in The Possibility of Altruism (Nagel 1970). ${ }^{22}$ According to this theory, the fact that an action would serve to satisfy someone's desire is a reason for everyone to enable, promote, or perform that action, even those people who themselves have no

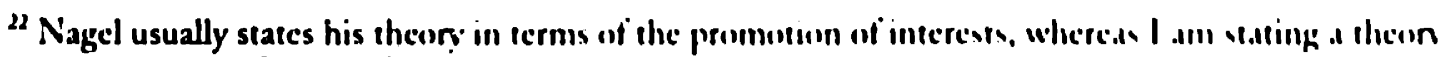
the focuses on the satisfaction of devires
} 
desires that would be served by serving other people's desires. From a naturalistic point of view, facts about whether or not someone's desires will be served by the performance of some action are perfectly respectable facts. Yet this is not an agent-centered theory of reasons for action. So, the fact that we must analyze reasons for action in terms of facts that are themselves acceptable from a naturalistic perspective does not, by itself, require the agent-centered aspect of his theory.

Nor does it require analyzing reasons for action in terms of desires, either the agent's desires or anyone else's. There are a host of naturalistically acceptable facts that have nothing to do with desires and that are nonetheless plausible candidates for facts which are reasons for agents to perform certain actions. Remember, a reason for an agent to perform an action is a fact that is favorably relevant to its being the case that the agent ought to perform the action, and there seem to be lots of facts that are not about the agent's desires but that are nonetheless prime candidates for being facts that are relevant to what the agent ought to do. For example, the fact that $A$ gave $B$ five dollars on the condition that he would pay it back seems to be a prime candidate for a fact that is favorably relevant to its being the case that $B$ ought to give $A$ five dollars, and so seems to be a prime candidate for being a reason for B to give A five dollars. Yet it is perfectly respectable naturalistic fact.

So the claim that we must analyze reasons for action in terms that are acceptable from a naturalistic perspective does nothing, by itself, to establish Harman's agentcentered, desire-based theory of reasons for action.

5.4 The second argument at work in the passage is one that hinges on the relation between reasons and motivation. Because I have been carrying out this discussion in terms of 'a reason' and 'motivation', whereas Harman's passage is stated in terms of 'sufficient reasons' and 'intentions', we will have to do a bit of translating to sec how 
Harman's point bears on our discussion. Harman says that if an agent has overriding reason to perform an action, and yet fails to intend to perform the action, then this must be due to some "empirically discoverable failure." And what his examples of empirically discoverable failures come to, with one exception, is that the agent be fully rational and fully informed of all the non-practical facts. The one exception is weakness of will, but I don't think Harman should have included this on his list. To exhibit weakness of will is to give in to a strong desire to do something despite believing that there are compelling reasons not to do so. But allowing the agent to have beliefs about what reasons there are, together with the condition that the agent be fully informed, is going to open up the Narrow Desire Argument to the objection I gave to the non-narrow Desire Argument in Section 4. Setting weakness of will aside, then, what we seem to have is that there are overriding reasons for an agent to perform an action if and only if the agent would intend to perform the action were he fully rational and fully informed of all and only the nonpractical facts. Now, if that is the correct account of there being overriding reasons for action, then it seems plausible to also give an account of there being some reason for action by saying that there is a reason for an agent to perform an action if and only if the agent would be motivated to some extent to perform the action, were he fully rational, and fully informed of all and only the non-practical facts. That is, Harman would have us endorse the following claim:

Strong Reasons Internalism: There is a reason for an agent to perform an action if and only if the agent would be motivated to some extent to perform it, were he fully rational and fully informed of all and only the non-practical facts.

I call this Strong Reasons Internalism because it ties the existence of motivation to the existence of reasons, even though the agent in question has no beliefs one way or the other about what reasons there are. 
It is the requirement that we give a naturalistically acceptable account of the link between reasons and motivation, as expressed in Strong Reasons Internalism, that provides Harman with grounds for focusing on facts about desires, and, more specifically, for focusing on facts about the agent's own desires. According to the Humean Theory of Motivation, an agent will be motivated to perform an action if and only if he has a desire that he believes will be served by his performing the action. And an agent who is fully informed about what actions will actually serve his desires will be motivated to perform an action if and only if he actually has a desire that will be served by his performing that action. So, the Humean Theory of Motivation, together with Strong Reasons Internalism, yields (Pr). Thus, Harman opts for the agent-centered, desire based theory of reasons for action expressed in (PI) because he thinks it is the only way to give a naturalistically acceptable account of the tight link between motivation and reasons for action expressed in Strong Reasons Internalism.

5.5 But Strong Reasons Internalism is implausible. I agree with Harman that there is a link between reasons and motivation, as evidenced by the fact that I appealed to Reasons Internalism in my argument that Harman's description of Villain begged the question against the Moral Universalist. Recall that Reasons Internalism says that if an agent is fully rational and if he believes that there is a reason for him to perform some action, then he will be motivated to some extent to perform it. But the motivational link indicated by Reasons Internalism is mediated by the rational agent's belief about his reasons for action, and this is the key to its plausibility. Once this mediating belief is dropped, as it is in Strong Reasons Internalism, it is no longer plausible to suppose that an agent who is fully rational and informed of all and only the non-practical facts, will always be motivated to do that which there is a reason for him to do. This is because a reason for an agent to perform an action is a fact that is favorably relevant to its being the 
case that the agent ought to perform the action, and it seems very plausible to suppose that there are facts that are relevant to what an agent ought to do that do not link up in the right way with that agent's desires. When the agent reflects on such a fact, he may fail to be motivated by it because it lacks the proper connection with his desires, not because it is not a reason. To continue with the example of the fact that $A$ gave $B$ five dollars on the condition that he would pay it back, would we even expect that fact to motivate B to repay the five dollars if we at the same time assume that $B$ has no desires that would be served by his doing so? We can suppose that B has no desire to pay the money back, nor does $B$ ever desire anything from $A$ that he won't get if $A$ is mad at him for not paying the money back, nor does he have a desire to do what morality requires of him. It seems to me that if B lacks all those desires, then B would not bs motivated to repay the money. Yet I see no reason for thinking that this lack of motivation on B's part undermines the claim that it is a fact that is favorably relevant to its being the case that B ought to repay the money. So Strong Reasons Internalism looks implausible when we examine its implications for particular cases.

5.6 It will be instructive here to look at John Mackie's discussion of the relationship between reasons and motivation (Mackie 1977, 27-42). In arguing for his error theory, Mackie says that if anyone were morally required to perform an action, then there would be "a reason for acting which was unconditional in the sense of not being contingent upon any present desire of the agent to whose satisfaction the recommended action would contribute as a means" (Mackie 1977,39 ). But there couldn't be any such reason, Mackic says, for if there were, it would motivate the agent independently of any desire the agent 
has, and nothing motivates independently of desires (Mackie 1977,40 ). ${ }^{23}$ Hence, Mackie concludes, no one is morally required to do anything.

Harman agrees with Mackie in that he also thinks that motivation doesn't occur independently of desires, but he disagrees with Mackie in that he thinks that someone can be morally required to do something without there being a reason for acting which was unconditional upon the agent's desires: that there be a reason based upon the agent's desires is enough. I am inclined to think that Mackie is right: moral requirements are reasons for action that are unconditional upon the agents desires, and I am inclined to think that both Mackie and Harman are right that motivation doesn't occur independently of desires. But I think that both are wrong in thinking that there is a very tight connection between reasons for action and motivation. As Mackie himself observed, moral requirements seem to provide reasons for action that are independent of the agent's desires. It was only Mackie's implausible belief that such reasons would also motivate independently of the agent's desires that forced him to conclude what he himself granted was extremely counterintuitive, that there couldn't be any reasons for action that are independent of the agent's desires.

So proper naturalistic scruples do not require an agent-centered, desire-based view of reasons for action, nor does the appropriate understanding of the relation between reasons for action and motivation require our adopting Strong Reasons Internalism. Instead, it seems plausible to suppose that there is a class of naturalistically acceptable facts that are reasons for action, but which can be unconnected with the agent's desires, and when they are unconnected with the agent's desires, do not motivate the agent unless the agent is fully rational and aware that those facts are reasons for action.

\footnotetext{
". Mackic's view is even stronger than Strong Reasons Internalism. According to Mackic, a fact that is a reason fior an agent to perform an action motivates that agent to perform that action if he is aware of it, where... Sirmong Reduns Internalism just says that it motivates him if he is aw:are of it and he is rational.
} 
5.7 In short, neither the Desire Argument nor the Narrow Desire Argument can be used in defense of the Reasons Relativism. The Moral Universalist could plausibly claim to have an argument which showed that any fully rational, fully informed agent would have a desire to do what morality required of him, and so could reject the Desirc Argument. And the Narrow Desire Argument rested on an implausibly tight connection between the reasons there are for an agent to perform an action and the agent's motivations.

\section{Summary}

6.I When agents are subject to different moral requirements, this is to be explained in terms of their different circumstances and the application to both of them of some more qualified moral requirement that takes these different circumstances into account. This provides us with an argument for Moral Universalism. But if Moral Universalism is truc, then we must find a response to the Practicality Argument. The first premise of the Practicality Argument was the Practicality Requirement, which says that if morality requires an agent to perform an action, then there is a reason for him to perform it. I argued that denying the Practicality Requirement is implausible. Therefore, we need to find grounds for rejecting the second premise of the Practicality Argument, Reasons Relativism. Reasons Relativism says that for any action, there is some agent such that there is no reason for that agent to perform that action. The first argument for Reasons Relativism, the Desire Argument, begged the question against the Moral Universalist. The second argument for Reasons Relativism, the Narrow Desire Argument, rested on an implausibly tight connection between an agent's reasons for action and the agent's motivation. In the absence of further argument, the Moral Universalist is therefore free to reject Reasons Relativism, and with it, the Practicality Argument for Agent Relativism. 
$\therefore$ 


\section{Chapter Three \\ Reasons for Action and the Ways of Being Good}

\section{The Project}

I.I As the term 'reason' is normally used, a reason is a consideration in favor of an action. More precisely, a reason for an agent to do something is a consideration in favor of that agent's doing that thing. Reasons, in this sense, connect up with what an agent ought to do. When someone asks why be ought to do something, what he is asking for are the reasons there are for him to do that thing; he is asking for those considerations that are in favor of his doing that thing. So a reason for an agent to perform an action is a fact that is favorably relevant to its being the case that he ought to do that thing. ${ }^{24}$ Of course, there can be both reasons for and against an agent's doing something, and so when someone asks whether be ought to do something, what he is asking is whether the reasons there are for him to do it outweigh, are stronger than, or, as I shall put it, override the reasons there are for him not to do it. If they do, and only if they do, then the agent ought to perform the action.

It is a popular idea, and one that seems right to me, that one ought to always comply with one's moral requirements. Alternatively put, it is a popular idea that there are always overriding reasons to comply with one's moral requirements. Call this the Autbority of Morality:

The Authority of Morality: If morality requires $A$ to $\phi$, then there are overriding reasons for $\mathrm{A}$ to $\phi$.

\footnotetext{
${ }^{24}$ Sec (Thornson 1990, 12-15).
} 
Perhaps the central question in metaethics is the question of whether the Authority of Morality is true, and if it is true, why it is true. I propose to set that question aside. It's too difficult. Let us instead focus on a more modest thesis, which I will call the Relevance of Morality:

The Relevance of Morality: If morality requires $A$ to $\phi$, then there is a reason for $A$ to $\phi$.

The Relevance of Morality is more modest than the Authority of Morality in that it says only that there is $a$ reason to comply with one's moral requirements, whereas the Authority of Morality says that there are overriding reasons to comply with one's moral requirements.

Is the Relevance of Morality true, and if it is true, why is it true? Well, the Authority of Morality entails the Relevance of Morality, and as I am inclined to think that the Authority of Morality is true, I am inclined to think that the Relevance of Morality is true as well. But I won't argue for its truth here. Rather, I will take its truth for granted, and focus entirely on the question of why it is true. What plausible story can we tell about morality and about reasons for action so that it turns out that the Relevance of Morality is true?

I.2 It is clear that on many accounts of reasons for action, the Relevance of Morality turns out to be false. For example, many philosophers believe that the reasons there are for an agent to do something must be grounded in that agent's desires or interests: if an action would in no way further the agent's interests or the satisfaction of the agent's desires, then there is no reason for the agent to perform that action. Such views are inconsistent with the Relevance of Morality, for it is possible for an agent to be morally required to do something which in no way furthers the agent's interests or the satisfaction of the agent's desires. 
If the reasons there are for an agent to do something are not grounded in that agent's interests or desires, what are they grounded in? What else could provide the grounds for reasons for action, and do so in a way that would provide a plausible explanation of the Relevance of Morality? One basis for reasons for action that many people have found attractive is goodness. Facts to the effect that an action would be good or would promote the good seem to be relevant to what ought to be done. Further, since it is a common idea that morality is concerned with the good, a good-based theory of reasons for action seems to hold out promise for providing a plausible explanation of the Relevance of Morality.

I.3 But what if there is no such thing as goodness? A number of philosophers have argued against the existence of goodness on the basis of linguistic intuitions about the way the word 'good' and its cognates are used. ${ }^{25}$ Judith Thomson, the philosopher on whom I will be focusing, appeals to linguistic intuitions to argue that there is no such thing as goodness; there are only what she calls "the ways of being good." Her argument for this conclusion is straightforward: whenever anyone says 'That's good' of something, we don't know what that person has said unless the context makes it clear in what way the thing referred to is being said to be good. But if there were such a thing as pure, unadulterated goodness, then we wouldn't need to know the way in which the thing was being said to be good in order to understand what was being said, for what was being said might simply be that the thing referred to is good.

In examining the implications of this view, Thomson makes two suggestions about the ways of being good, cne about how they relate to moral requirements and the other about how they relate to reasons for action. ${ }^{26}$ In this chapter, I want to combine these

\footnotetext{
"Sec (Geach 1956), (Ziff 1960), (Von Wright 1963), (Thomson 1997), and (Thomson 1992:1).

in Thomson explains her view of the connecrion between the ways of being goond and morril requirements in (Thomson 1997) and she explains her view of the connection berween the way's of being grend and redsuns for action in (Thomson r999).
} 
two suggestions with an eye to investigating whether they provide a plausible story according to which the Relevance of Morality turns out to be true. The conclusions of my investigation will be mixed. I will conclude that while there is much to be said in favor of the two theses and of the account they provide of the Relevance of Morality, problems remain in the form of distinctions which, despite being intuitively plausible, remain in need of theoretically satisfying explanations. Before turning to that investigation, though, some remarks about the way in which $I$ intend to use the term 'reason' are in order.

1.4 We need to distinguish between there being a reason for an agent to do something, and an agent's having a reason to do something. For an agent to have a reason to do something is for it to be the case that what the agent takes to be a reason for him to do that thing really is a reason for him to do that thing. There are two kinds of cases in which there is a reason for an agent to do something even though the agent does not have that reason as his reason for doing that thing. First, there may be a reason of which the agent is unaware, in which case the agent won't take it to be a reason. For example, Smith may be unaware that his taking a certain medicine will make him feel better, but that it will make him feel better may still be a reason for him to take the medicine. If Smith takes the medicine at all, then bis reason for doing so will not be that his taking it will make him feel better. Second, there may be a reason that an agent is aware of, but which he simply doesn't believe is a reason. For example, Jones may be aware that his taking a certain medicine will lower his blood pressure, and it may be that, unbeknownst to Jones, his blood pressure is dangerously high and so there is a reason for him to lower his blood pressure. But if Jones thinks that his blood pressure is just fine where it is, then he will not take the fact that his taking the medicine will lower his 
blood pressure to be a reason for him to take the medicine. If he takes the medicine at all, his reason for doing so will not be that his taking it will lower his blood pressure.

Is it possible for there to be a case in which an agent has a reason to do something even though there is no reason for him to do that thing? Not if we understand the relationship between there being a reason and an agent's having a reason as I intend to. I had said that for an agent to have a reason to do something is for it to be the case that what the agent takes to be a reason for him to do that thing really is a reason for him to do that thing. But if there really isn't any reason for, say, Alfred to kiss a certain frog, then no matter what Alfred takes to be a reason for him to kiss a frog, what he takes to be a reason isn't really a reason. ${ }^{27}$

With the distinction between there being a reason and an agent's having a reason in hand, it is important to note that the Relevance of Morality does not say that if morality requires an agent to do something, then that agent has a reason to do that thing. An agent may be unaware of a moral requirement, in which case he won't take the fact that he has a moral requirement to be a reason. Or, he may be aware of a moral requirement, but deny that facts about moral requirements are relevant to what he ought to do, in which case he again won't take the fact that he has a moral requirement to be a reason. The Relevance of Morality is a thesis about what reasons there are, not about what reasons agents have.

\section{The Ways of Being Good and Moral Requirements}

2.I So we want to know whether an account of reasons for action that is based on the ways in which an action can be good provides a plausible explanation of the Relevance of Morality. The first part of our project is to understand how the ways of being good relate to moral requirements. Thomson suggests that the relationship lies in

\footnotetext{
2: Compare: can an agent have cvidence for thinking that Jones committed a certain murder if there is no evidence for thinkıng that Jones committed the murder? Intuitively, the answer is no.
} 
the fact that morality requires avoiding actions that are morally bad in some way (Thomson 1997, 286). This needs explanation, and to that end, I will briefly summarize those parts of Thomson's view of the ways of being good that are germane to our project.

2.2 Thomson's view of the ways of being good is, very briefly, the following. First, there is no such property as goodness. ${ }^{2 \mathrm{~B}}$

Second, despite their being no such property as goodness, there are what she calls the ways of being good. A property $F$ is a way of being good if and only if it is a property that can be ascribed to a thing by saying of it 'That's good' or 'That would be good' or 'He's good' or 'She's good' or some such phrase. The ways of being good include being good to eat, being good for Alfred, being good as Hamlet, being good for use in making cheesecake, being good with children, and being good at hanging wallpaper. Further, there are the ways of being aesthetically good (for example, being pretty and being graceful) and, of particular importance to us, the ways of being morally good (for example, being just, being honest and being kind). ${ }^{29}$

2.3 We need to guard against a possible misinterpretation of Thomson's view here, for her terminology of "the ways of being good" is potentially misleading in two ways. Normally, if there is such a thing as a way of being F, there is also such a thing as the

\footnotetext{
${ }^{28}$ Thomson also argues that there is no such thing as being a good $K$, for some $K$. Rather, what is said when someone utters a sentence of the form ' $X$ is a good $K$ ' is equivalent, for some way of being good, to the proposition that $X$ is a $K$ and $X$ is good in that way. For example, what is said when someone utters 'This is a gond book' is, in most contexts, equivalent to the proposition that this is a book and it is good (n) read. Or, what is said when someone utters 'Alice is a good person' may he equivalent to the proposition that Alice is a person and Alice is just. But if the context docsn't make it clear which way of heing $h^{\prime \prime m e x t}$ the person means to be ascribing, then we simply don't kmow whot the person is sdying when they utler a

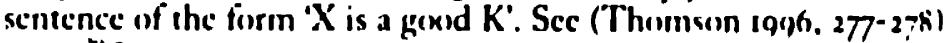

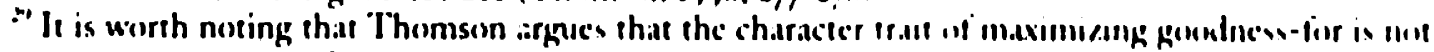
aviruce, nor are courage, industriousness, ur liw alss:
} 
property of being F. On Thomson's view, though, there are only the ways of being good; the property of being good doesn't exist.

As an example of the normal case, consider that there are lots of ways to eat a Reese's Peanut Butter Cup, and there is also such a thing as the property of eating a Reese's Peanut Butter Cup. An agent has that property if and only if, for some way of eating a Reese's Peanut Butter Cup, the agent is eating a Reese's Peanut Butter Cup in that way. So, Jones is eating a Reese's Peanut Butter Cup if and only if he is eating one quickly or slowly or normally, and so on, for the rest of the ways in which one can eat a Reese's Peanut Butter Cup. But this situation, in which there are both the ways of eating a Reese's Peanut Butter Cup and the property of eating a Reese's Peanut Butter Cup, contrasts with Thomson's view of the good, for Thomson rightly rejects the attempt to define goodness as an existential generalization over the ways of being good (Thomson 1997, 277). She says that the property that a thing has if and only if it is good in some way or other is certainly not the property that friends of goodness mean to be talking about when they speak of goodness. Everything is good in some way or other, but friends of goodness mean to be speaking of a property such that it makes sense to deny of some things that they have that property. They want to distinguish the actions that are good from those that are not, or the people that are good from those that are not, or the states of affairs that are good from those that are not. But if goodness were the property of being good in some way or other, there would be no such distinctions to be drawn. Even a person that the friends of goodness would say is bad is good for use as an example of someone not to emulate.

The second way in which Thomson's terminology of "the ways of being good" is potentially misleading emerges as follows. When we predicate 'is eating a Recse's Peanut Butter Cup' of someone, we do not say, for some way of eating it, that he is eating it in that way. If someone says 'Jones is eating a Reese's Peanut Butter Cup', he has not said that Jones is eating a Recse's P'eanut Butter Cup quickly, nor has he said that Jones is 
eating a Reese's Peanut Butter Cup messily, nor has he said, for any other way of eating a Reese's Peanut Butter Cup, that Jones is eating a Reese's Peanut Butter Cup in that way. What he has said leaves it entirely open in which way Jones is eating a Reese's Peanut Butter Cup, and this is because all that the speaker said was that Jones is eating a Reese's Peanut Butter Cup. This contrasts, say, with someone who says 'Jones is tall'. Someone who says 'Jones is tall' has said, for some comparison class $\mathrm{K}$, that Jones is tall for a K. And if we don't know what comparison class the speaker had in mind, then we simply don't know what the speaker has said. In this respect, the ways of being good are like being tall, and are unlike being a way of eating a Reese's Peanut Butter Cup.

Thomson also sometimes expresses these two theses by saying that "a thing's being good just is its being good in this or that way" (Thomson 1992a, 149), but if there is no such property as being good, states of affairs that consist in a thing's being good do not exist, and a fortiori are not identical with a thing's being good in this or that way.

2.5 With Thomson's view of the ways of being good summarized, let us now turn to the relationship between the ways of being good and moral requirements. Thomson defines a virtue property as a property $\mathrm{F}$ such that there is a character trait consisting in proneness to performing F-ish acts, and that character trait is a virtuc. So being just is a virtue property because chere is a property, viz., being just, such that there is a character trait, viz., justice, consisting in proneness to performing just acts, and that character trait is a virtue. Being kind and being generous are also virtue properties. Being graceful, on the other hand, is not a virtue property because the character trait of being graceful is not a virtue.

Let us say that being just, being kind, being generous, and so on for the rest of the virtue properties, are ways in which an action can be virtuous. And let us say that an action is virtuous if and only if, for some way of heing virtunus, the action is virtumu in that 
way. If an action is just, then the action is virtuous, and the way in which it is virtuous is that it is just. ${ }^{30}$ Let us say that being unjust, being cruel, being mean, and so on for the rest of the contraries of the virtue properties, are ways in which an action can be vicious." And let us say that an action is vicious if and only if, for some way of being vicious, the action is vicious in that way. So if an action is unjust, then the action is vicious, and the way in which it is vicious is that it is unjust.

Thomson says that morality requires an agent to do something if and only if the agent's not doing that thing would be vicious in some way. Now, if $\mathrm{W}$ is a way in which an action can be vicious and if $W$ is also a way of being bad, then let us say that $W$ is a way of being morally bad. So if being unjust, which is a way in which an action can be vicious, is also a way of being bad, then being unjust is a way of being morally bad, and unjust actions are morally bad in that way. Analogously, if $\mathrm{W}$ is a way in which an action can be virtuous and if $\mathrm{W}$ is also a way of being good, then let us say that $\mathrm{W}$ is a way of being morally good. So if being just, which is a way in which an action can be virtuous, is also a way of being good, then being just is a way of being morally good, and just actions are morally good in that way.

Why distinguish between the ways in which an action can be virtuous or vicious and the ways in which an action can be morally good or morally bad? Because there are those who would say that some of the ways in which an action can be virtuous are not ways of being good and so are not ways of being morally good. And there are those who say that some of the ways in which an action can be vicious are not ways of being bad and so are not ways of being morally bad. That is, there are those who would say, for example, that being chaste is a way of being virtuous, but it isn't a way of being good, and a fortiori,

\footnotetext{
${ }^{30}$ Notice that unlike goodness, being virtuous is properly defined as an existential generalization over the ways in which an action can be virtuous. Sec (Harman and Thomson 1996, 185).

Notice that a virtue property and its contrary are not collectively exhaustive. My tying my shoc wis neither kind nor cruel. Is it possible for an action io have both a virtuc property and also the contrany of a virtue property? I am going to assume without argument that this is not possible.
} 
isn't a way of being morally good. They would say that being chaste is an aspect of morality that is old-fashioned, obsolete, or out-of-date, but is nonetheless still an aspect of morality. I'm not suggesting that such people are correct in saying such things; indeed, they seem to me to be obviously mistaken. The point is only that this sort of view is not ruled out by definition. It is a substantive claim that the ways of being virtuous are ways of being good, and that the ways of being vicious are ways of being bad.

So, according to Thomson, morality requires an agent to do something if and only if, for some way of being vicious, the agent's not doing that thing would be vicious in that way. But, Thomson says, the ways of being vicious are ways of being bad, and so morality requires an agent to do something if and only, for some way of being morally bad, the agent's not doing that thing would be bad in that way. For the purposes of providing an explanation of the Relevance of Morality, we only need the weaker claim that if morality requires an agent to do something, then, for some way of being morally bad, the agent's not doing that thing would be bad in that way. And of course, if the agent's not doing that thing would be bad in that way, then it is a fact that the agent's not doing that thing would be bad in that way. Hence, if morality requires an agent to do a thing, then for some way of being morally bad, it is a fact that the agent's not doing that thing would be bad in that way. Let us call this the Moral Requirements Thesis:

The Moral Requirements Thesis: If morality requires $A$ to $\phi$, then for some way of being morally bad, it is a fact that A's not $\phi$-ing would be bad in that way.

The Moral Requirements Thesis tells us how moral requirements are related to the ways in which an action can be bad. Let us now turn to the second part of our project: understanding how the ways in which an action can be bad relate to reasons for action. I will begin with Thomson's view from (Thomson 1999). 


\section{The Ways of Being Good and Reasons for Action}

3.1 Thomson suggests that ways of being good relate to reasons for action in the following way: a fact $F$ is a reason for an agent to perform an action if and only if, for some way of being good, $\mathrm{F}$ is the fact that the action would be good in that way (Thomson 1999, 13). ${ }^{32}$ Let us call this the Reasons for Action Thesis:

The Reasons for Action Thesis: $A$ fact $F$ is a reason for $A$ to $\phi$ if and only if, for some way of being good, $F$ is the fact that A's $\phi$-ing would be good in that way.

For example, if Jones's taking a certain medicine would be good for him, then according to the Reasons for Action Thesis, the fact that his taking the medicine would be good for him is a reason for him to take the medicine. Or, if Jones's taking a certain medicine would be good for Smith (Smith is somehow relying on Jones's feeling well), then according to the Reasons for Action Thesis, the fact that Jones's taking the medicine would be good for Smith is again a reason for Jones to take the medicine.

Let me now argue for making two preliminary amendments to the Reasons for Action Thesis, amendments which I think leave the overall spirit of the Reasons for Action Thesis intact.

3.2 First, it seems intuitively plausible to think that if $\mathrm{F}$ is, for some way of being bad, the fact that A's not $\phi$-ing would be bad in that way, then F is a reason for A to $\phi$. But according to the Reasons for Action Thesis, $F$ isn't a reason for $A$ to $\phi$, for $F$ is a fact about the way in which A's $\phi$-ing would be bad, not good. It might be tempting to avoid this complication by supposing that the fact that A's $\phi$-ing would be good in way $\mathrm{W}$ is necessarily coextensive with the fact that A's not $\phi$-ing would be bad in the way that is the contrary of $W$, and if those facts are necessarily coextensive, we might as well

\footnotetext{
${ }^{12}$ Thomson actually says that a fact $F$ is a reasion for an agent to perform an action if and only if, for wine way of being good, $F$ is the fact "to the effect" that the action would be good in that wily. For hrevity, I omit the "to the effect" here and throughoute the rest of the chapter.
} 
identify them. On this supposition, if A's not $\phi$-ing would be unjust, then the fact that A's not $\phi$-ing would be unjust is identical to the fact that A's $\phi$-ing would be just, and so would be a reason for $A$ to $\phi$ by the Reasons for Action Thesis.

But the fact that A's $\phi$-ing would be good in way $W$ is not necessarily coextensive with the fact that A's not $\phi$-ing would be bad in the way that is the contrary of $W$. Let us suppose that Smith's taking a certain medicine would be good for him because it would cure his illness. Does it follow that Smith's not taking that medicine would be bad for him? Not necessarily, for Smith might instead simply take a different medicine which would also cure his illness. Similarly, it may be that Smith's giving a five dollar bill to Jones would be just, even though his not giving the five dollar bill to Jones would not be unjust, say, if he instead gave Jones five one dollar bills. But if the requisite facts are not necessarily coextensive, then we cannot identify them, and we cannot avoid adding a clause about the ways of being bad to the Reasons for Action Thesis.

3.3 The second way in which the Reasons for Action Thesis needs to be amended einerges as follows.

Suppose that Jones's taking a certain medicine would cure his sickness, and would therefore be good for him. According to the Reasons for Action Thesis, the fact that Jones's taking the medicine would cure his sickness is not itself a reason for him to do so, for it is not itself the fact that Jones's taking the medicine would be good for him. (His taking the medicine could be good for him even if, for example, it only alleviated the unpleasant symptoms of his sickness without actually curing it.) Thomson would say that it is at best a reason to believe that Jones's taking the medicine would be good in some way (Thomson 1999, 13). I think this aspect of the Reasons for Action Thesis should be rejected. 
The fact that Jones's taking the medicine would cure his sickness is not merely a reason to believe that Jones's taking the medicine would be good for him: it is part of the explanation why his taking the medicine would be good for him. The explanation why his taking the medicine would be good for him is that it would cure his sickness, and that would be good for him. The fact that Jones's taking the medicine would cure his sickness contrasts with a fact such as the fact that his friend advised him to take the medicine. The fact that Jones's friend advised him to take the medicine is merely a reason to believe that his taking the medicine would be good for him. It is not part of the explanation why his taking the medicine would be good for him (although it might be part of the explanation why he took the medicine, for he might have taken it because his friend advised him to). And I think, intuitively, the fact that his friend advised him to take the medicine is not itself a reason for Jones to take the medicine. Jones's friend could advise Jones to do something that there is no reason for Jones to do.

Why count facts that are part of the explanation of why an action would be good in some way as reasons for the action? There are two reasons. First, doing so accords better with ordinary usage. If we ask Jones what reasons there are for him to take the medicine, he might respond by saying that his taking the medicine would be good for him, but he might also respond by saying that his taking the medicine would cure his sickness. Indeed, I think it more likely that he would respond in this second way. It's more informative. And there seems nothing odd or out of the ordinary in his doing so.

And second, the definition of reasons for action that I gave at the beginning of the chapter requires that we allow facts that are part of the explanation of why an action would be good in some way to be reasons for action. According to that definition, a reason for $A$ to $\phi$ is a fact that is favorably relevant to its being the case that $A$ ought to $\phi$, and there are lots of facts that are relevant in that way even though they are not themselves facts about the way in which A's $\phi$-ing would be good. For example, the fact that lones saking the medicine would cure his sickness is, in the imagined 
circumstances, favorably relevant to its being the case that he ought to take the medicine, but it is not identical to the fact that Jones's taking the medicine would be good for him.

3.4 We can still preserve the spirit of the Reasons for Action Thesis, though, by allowing that the fact that Jones's taking his medicine would cure his sickness is a reason for him to take his medicine only if that fact is part of the explanation of why his taking his medicine would be good in some way. Further, while the fact that Jones's taking the medicine would cure his sickness and the fact that Jones's taking the medicine would be good for him are two different facts, and so are two different reasons, they are not independent reasons: the first is derivative from the second. This contrasts with a case in which Jones's taking the medicine would be good for Jones (because it would cure his sickness), and would also be good for Smith (because Smith is somehow relying on Jones's feeling well).

So, $I$ think we should allow that a fact $F$ can be a reason for $A$ to $\phi$ even though $F$ is not itself, for some way of being good, the fact that A's $\phi$-ing would be good in that way. It's enough that it be part of the explanation why A's $\phi$-ing would be good in that way Amending the Reasons for Actions Thesis to take into account these two points requires amending it so as to allow that a fact $\mathrm{F}$ is a reason for $\mathrm{A}$ to $\phi$ if and only it meets any of the following conditions: 
(i.a) For some way of being good, $F$ is the fact that A's $\phi$-ing would be good in that way.

(i.b) For some way of being bad, $F$ is the fact that $A$ 's not $\phi$-ing would be bad in that way.

(ii.a) For some way of being good, $F$ is part of the explanation why A's $\phi$-ing would be good in that way.

(ii.b) For some way of being bad, $F$ is part of the explanation why $A$ 's not $\phi$ ing would be bad in that way.

If a fact meets one of those conditions, let us say that it is "suitably related to some way in which A's $\phi$-ing (A's not $\phi$-ing) would be good (bad)." Let us therefore revise the Reasons for Action Thesis to read as follows:

The Revised Reasons for Action Thesis: $A$ fact $F$ is a reason for $A$ to $\phi$ if and only if $F$ is suitably related to some way in which A's $\phi$-ing (A's not $\phi$-ing) would be good (bad).

\section{The Quick Argument for the Relevance of Morality}

4.I So we have in hand two interesting and prima facie plausible suggestions. First, we have the Moral Requirements Thesis:

The Moral Requirements Thesis: If morality requires $A$ to $\phi$, then for some way of being morally bad, it is a fact that A's not $\phi$-ing would be bad in that way.

Second, we have the Revised Reasons for Action Thesis:

The Revised Reasons for Action Thesis: $A$ fact $F$ is a reason for $A$ to $\phi$ if and only if $F$ is suitably related to some way in which A's $\phi$-ing (A's not $\phi$-ing) would be good (bad).

Putting these two theses together yields a quick argument for the Relevance of Morality. Suppose that morality requires Jones to dance. Then by the Moral Requirements Thesis, for some way of being morally bad, it is a fact that Jones's not dancing would be bad in that way. But according to the Revised Reasons for Action Thesis (by clause (i.b)), that fact is itself a reason for Jones to dance. So there is a reason for Jones to do what morality requires. More generally, we have the following argument for the Relevance of Morality: 


\section{The Quick Argument for the Relevance of Morality}

(PI) If morality requires $A$ to $\phi$, then for some way of being morally bad, it is a fact that A's not $\phi$-ing would be bad in that way. (The Moral Requirements Thesis)

$\left(\mathrm{P}_{2}\right) \quad \mathrm{A}$ fact $\mathrm{F}$ is a reason for $\mathrm{A}$ to $\phi$ if and only if $\mathrm{F}$ is suitably related to some way in which A's $\phi$-ing (A's not $\phi$-ing) would be good (bad). (The Revised Reasons for Action Thesis)

(C) Hence, if morality requires $A$ to $\phi$, then there is a reason for $A$ to $\phi$.

What should we make of this argument? In Section 5, I will indicate some of its attractions. I also think we should accept its first premise, the Moral Requirements Thesis, and will defend that thesis against one objection in Section 6. But I will argue that the argument's second premise, the Revised Reasons for Action Thesis is false, and hence, that the Quick Argument for the Relevance of Morality is unsound.

\section{Some Advantages of the Quick Argument for the Relcvance of Morality}

5.I It will be worthwhile to briefly compare the Moral Requirements Thesis, the Revised Reasons for Action Thesis, and the explanation they provide for the Relevance of Morality with two other views. I think this will bring out some of its theoretical and intuitive advantages. In many ways, it is an attractive view.

5.2 Gavin Lawrence opts for a good-based account of reasons for action according to which it is conceptually true that there is a reason for $A$ to $\phi$ if and only if A's $\phi$-ing would be good. A fortiori, it is true that there is a reason for A to $\phi$ if and only if A's $\phi$ ing would be good. What is it for A's $\phi$-ing to be good? Lawrence says that it is for A's $\phi$-ing to be virtuous. ${ }^{33}$ It follows that if A's $\phi$-ing would be virtuous, then there is a reason for $\mathrm{A}$ to $\phi$.

There are three problems with Lawrence's account, problems that the Quick Argument for the Relevance of Morality bypasses. First, Lawrence's account presupposes the existence of goodness, but there is no such thing as goodness. The Revised Reasons

\footnotetext{
"Sec (I.awrence togos)
} 
for Action Thesis clearly avoids this problem; it is put in terms of the ways of being good.

Second, Lawrence's claim that for A's $\phi$-ing to be good is for it to be virtuous is an excessively narrow understanding of the ways in which an action can be good, and it yields an excessively narrow account of reasons for action. An action can be good in some way without being virtuous; it could instead be graceful or charming. And there could be a reason for Jones to tie his shoe, for example, even though in the circumstances, his tying his shoe would not be virtuous in any way. Indeed, there could even be a reason for Jones to unjustly steal some money, namely, the fact that doing so would enable him to buy some delicious lemonade. The Revised Reasons for Action Thesis allows for these possibilities because an action can be good in lots of ways even though it is not virtuous.

Third, Lawrence is mistaken in thinking that it is conceptually true that there is a reason for $A$ to $\phi$ if and only if A's $\phi$-ing would be good. Lawrence says that the fact that his account is conceptually true means that the "formal object of practical rationality" is doing that which would be good, by which Lawrence means that if A takes the fact that his $\phi$-ing would be $F$ to be a reason for him to $\phi$, then, by his so taking it, $A$ thereby shows that he believes that his doing something $F$ would be good. For example, suppose Jones is asked why he should give to charity, and he responds by sincerely saying that he should give to charity because his doing so would be kind. Then, according to Lawrence, his responding in that way shows that Jones believes that his doing something kind would be good (Lawrence 1995, 130-132). According to Lawrence, then, the fact that his account is conceptually true implies that the only facts that someone can possibly take to be reasons for action are facts about what would be good.

Now, the view that the formal object of practical rationality is doing that which would he good seems false to me. Let us suppose that Alfred has been persuaded by varimu philowphers that there is no such thing as goodness. But he does helieve that 
there is such a thing as being good for someone, and so he opts for the popular idea that a fact $F$ is a reason for $A$ to $\phi$ if and only if $F$ is suitably related to A's $\phi$-ing (A's not $\phi$ ing) being good (bad) for $A$. Now, when Alfred deliberates about taking a trip to sunny Florida, he takes facts about whether it would be good for him to be reasons for action. He first tries to ascertain whether the trip would be good for him, and if he decides it would be, he concludes on that basis that there is a reason for him to take the trip. On the face of it, this seems to be a possible instance of practical reasoning. But, according to Lawrence, it is possible only if we can somehow find within Jones the belief that his doing what would be good for him would be good. But Alfred sincerely and repeatedly refuses to admit this, for he doesn't believe in goodness. In light of his sincere and repeated disavowals, supposing that he has this belief seems implausible. Rather, it seems that he believes only that his taking the trip would be good for him, and that the fact that it would be good for him is a reason for him to take it.

If the formal object of practical rationality is not doing that which would be good, what is? Well, suppose that Jones is asked why he should give to charity, and he responds by sincerely saying that he should give to charity because his doing so is kind. What does that show about Jones's beliefs? Only that he thinks that the fact that his doing so is kind is a reason for bim to do so. So I would make the banal suggestion that the formal object of practical rationality is doing that for which there is a reason, not doing that which would be good. ${ }^{34}$

Whether or not this suggestion is correct, the Revised Reasons for Action Thesis is not a theory of what people take to be reasons; it is, as I said, a theory about what reasons there are. It is therefore compatible with the view that people can take a fact to be a reason even if it they do not believe it to be a fact about what would be good, and this third objection to Lawrence's account does not apply to it.

\footnotetext{
${ }^{34}$ More accurately, 1 think that the formal object of practical rationality is doing that for which there are overriding reasons to do.
} 
5.3 Many people who might be attracted to an account of reasons for action based upon the ways of being good would nonetheless reject the Revised Reasons for Action Thesis, preferring instead the popular idea I mentioned above, that a fact $\mathrm{F}$ is a reason for $A$ to $\phi$ if and only if $F$ is suitably related to A's $\phi$-ing (A's not $\phi$-ing) being good (bad) for $A$. According to this popular idea, the only way of being good that ever matters is goodness-for, and the only way of being good that matters to the reasons for a particular agent $\mathbf{A}$ is goodness-for-A. Such a view, however, has difficulties accommodating our intuitions about reasons for action. Intuitively, facts about what would be good for others are relevant to what an agent ought to do. Moreover, it might be action would be just even though it was not good for anyone. That my returning Jones his cigarettes would be just (they are his, after all) is compatible with its being the case that my doing so is not good for him, nor for anyone else. Still, intuitively, the fact that the action would be just is a reason to perform it. Such a view is clearly going to have difficulties accommodating the Relevance of Morality, for it seems possible for morality to require an agent to do something that would not be good for that agent, but rather would be virtuous or good for some other agent.

The Revised Reasons for Action Thesis bypasses these difficulties, for according to it, the fact that A's $\phi$-ing would be good for someone other than $A$ is a fact that is suitably related to some way in which A's $\phi$-ing would be good, and so is a reason for A to $\phi$. Moreover, according to the Revised Reasons for Action Thesis, facts about the other ways in which an action would be good are also reasons to perform that action.

Here is an example that shows that the fact that an agerit's action would be good for someone other than the agent is a reason for that agent to perform that action. Suppose that it would be good for Alfred if his sickriess were cured. So anyone's action that would cure Alfred's sickness would be good for him, and so would be good in some way. 
It then follows from the Revised Reasons for Action Thesis that there is a reason for any person, no matter who that person is or how that person is related to Alfred, to perform such an action. But does the fact that it would be good for Alfred if his sickness were Ired really imply that there is a reason for, say, Queen Elizabeth to perform an action that would cure Alfred's sickness? ${ }^{35}$ The defender of the popular idea wo ild say no.

But, it seems to me that it does. Suppose that Queen Elizabeth needs to call one of her ministers. In order to do so, she has a choice of pushing a button on her left or a button on her right. If she pushes the button on her left, her minister will come. If she pushes the button on her right, her minister will come, and Alfred's sickness will be cured. Isn't there something to be said in favor of her pushing the button on her right? It seems to me that there is, viz., that her doing so would be good for Alfred. Suppose that the only difference between the Queen's pushing the button on her left and the button on her right is that if she pushes the button on her right, Alfred's sickness will be cured, whereas if she pushes the button on her left, Alfred's sickness wili not be cured. If that really is the only difference, it seems to me that all things considered, the reasons that there are for Queen Elizabeth to push the button on her right override the reasons for her to push the button on her left. Alternatively put, if that really is the only difference, she ought to push the button on her right, and so that difference is favorably relevant to its being the case that she ought to push the button on her right.

So I thin:: that there is a reason for Queen Elizabeth to push the button on her right. What is not plausible to say is that Queen Elizabeth bas the fact that her pushing the button on her right would be good for Alfred as a reason for her to push the button on her right. ${ }^{36}$ Queen Elizabeth is, in all likelihood, unaware of the fact that her pushing the button on her right will be good for Alfred, and even if she were aware of that fact,

\footnotetext{
"Thomson raises this question (Thomson $1092 \mathrm{~h}, 114)$.

"Sice (Thomson 1992b, 111-112) for Thomson's obsenations on how the word 'reason' slithers heween the reasons that there are for an agent und the rewem that an agent has.
} 
she might not care one whit about Alfred. In all likelihood, then, Queen Elizabeth will not take the fact that her pushing the button on her right will be good for Alfred to be a reason for her to do so, and she will in all likelihood have no such reason for pushing the button on her right. But that she has no such reason is consistent with there being such a reason, and so is consistent with the Revised Reasons for Action Thesis.

So facts about what would be good for others do seem to be reasons, and I therefore take it to be an advantage of the Revised Reasons for Action Thesis that it can accommodate that fact.

\section{The Moral Requirements Thesis}

6.I So the explanation for the Relevance of Morality provided by the Quick Argument for the Relevance of Morality is an attractive one. I know want to look directly at the premises of the argument itself. The first premise of the Quick Argument for the Relevance of Morality is the Moral Requirements Thesis. The Moral Requirements Thesis itself was the conclusion of a prior argument, which went as follows:

The Argument for the Moral Requirements Thesis

( $\mathrm{PI})$ Morality requires $A$ to $\phi$ if and only if, $A$ 's not $\phi$-ing would be vicious in some way.

$\left(\mathrm{P}_{2}\right)$ The ways of being vicious are ways of being bad, and so are ways of being morally bad.

(C) Hence, if morality requires $A$ to $\phi$, then, for some way of being morally bad, it is a fact that A's $\phi$-ing would be bad in that way.

I think this argument is sound, and want to defend it against an objection to $\left(\mathrm{P}_{2}\right)$. $\left(\mathrm{P}_{2}\right)$ says that the ways of being vicious are also ways of being bad, and so are ways of being morally bad. As I mentioned, it is not true by definition that the ways of being vicious are also ways of being bad. The question then arises as to why $\left(\mathrm{P}_{2}\right)$ is true. Well, for some property $P$, having the properny $P$ is a way of heing bad if and only if having the contran of $P$ is a way of heing geodd. Hence, the wayss of being vicious are ways of 
heing bad only if the ways of being virtuous are ways of being good. So: is it true that the ways of being virtuous are ways of being good?

Unfortunately, without an account of what marks something as a way of being good, no definitive answer can be given. Nonetheless, it will be useful to take a brief look at the example of kindness.

6.2 Is it true that being kind is a way of being good? Bruce Brower asks us to consider the following world, which he calls "W2":

W2: As a matter of psychological fact, kind people become weak and powerless. They are indecisive, lose control of their lives, and become ineffective in relations with others. Only those who are not kind can become strong and take charge of their lives. They need not be cruel or vicious, but even isolated kind acts lead to the destruction of one's character. (Brower 1988, 679) ${ }^{37}$

The conclusion Brower would have us draw about $\mathrm{W}_{2}$ is that "There is no reason for agents at $W_{2}$ to act kindly" (Brower 1988,683 ), but the challenge $W_{2}$ poses to $\left(P_{2}\right)$ is that some might be tempted to conclude that in $W_{2}$, being kind is not a way of being good. I don't think that this is right, though, and offer the following argument for thinking that even in $W_{2}$, being kind is a way of being good.

What would a world have to be like in order for it to be the case that, in that world, being kind is not a way of being good? It isn't enough, I think, that in that world, therc are further negative consequences to actions that are kind. It is highly implausible to think that an action that is good in some way can have no further negative consequences. I think that in order for a world to be such that, in that world, being kind is not a way of being good, actions which are kind in that world would have to lack those features of kind actions which, in our world, make it $t$ - case that being kind is a way of being good. And what makes being kind a way of being good in our world is not that kind

\footnotetext{
:- In thin yuufation. Brower m.akes stipulations about the psychology of kind people and about the

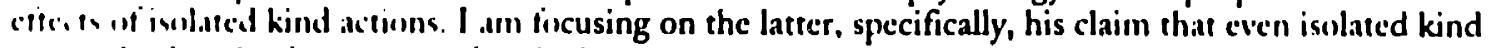

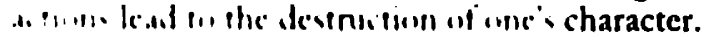


actions result in the agents who perform them being decisive, having control over their lives, and being effective in their relations with others. Thus, in $\mathrm{W}_{2}$, the fact that actions that are kind do not have those results leaves intact whatever features of being kind mark it as a way of being good. Thus, if being kind is a way of being good in our world, then it also a way of being good in $W_{2}$. Since it seems plausible to think that being kind is a way of being good in our world, I conclude that being kind is a way of being good in $\mathrm{W}_{2}$ as well.

Can a stronger argument be made that it is impossible for an action to be kind if it lacks those features that, in our world, makes it the case that being kind is a way of being good? If so, then we could establish not only that being kind is a way of being good in $\mathrm{W}_{2}$, but that being kind is a way of being good in any possible world. I leave this open.

It is also worth noting that, even though in $\mathrm{W}_{2}$ being kind is a still a way of being good, morality does not require an agent in $\mathrm{W}_{2}$ to perform kind actions: the cost to the agent is too great. This is consistent with the first premise of the Argument for the Moral Requirements Thesis, which says only that morality requires agents to refrain from performing vicious actions. It does not say that they are required to perform virtuous ones.

So it seems to me that the sort of possible world that Brower would have us consider is not a threat to either premise of the Argument for the Moral Requirements Thesis.

6.3 For what it is worth, I also think that Brower's claim that there is no reason for agents in $W_{2}$ to perform kind actions is mistaken. What is true in $W_{2}$ is that if $A$ 's $\phi$ ing would be kind, then A ought not $\phi$. That is, even though A's $\phi$-ing would be kind, there are nonetheless overriding reasons for $A$ not to $\phi$. But that is perfectly compatible with its heing the case that there is a reason for $A 10 \phi$ : it is just that it is built into the 
description of $W_{2}$ that any action which would be kind would also "lead to the destruction of one's character" and surely any reason for an action provided by the fact that it would be kind is outweighed by the reasons against that action provided by the fact that it would lead to the destruction of one's character.

So it is not true that in $\mathrm{W}_{2}$ agents ought to perform kind actions. Is it thue in $\mathrm{W}_{2}$ that any fact to the effect that someone's action would be kind is a reason for that person to perform that action? Intuitively, even in $\mathrm{W}_{2}$, that an action would be kind is something to be said in favor of it. So even in $\mathrm{W}_{2}$, the fact that the action would be kind is a reason to perform it. So not only do worlds like $W_{2}$ not pose any threat to the Moral Requirements Thesis, they also do not pose any threat to the Revised Reasons for Action Thesis.

\section{Difficulties for the Revised Reasons for Action Thesis}

7.I The second premise of the Quick Argument for the Re'vvance of Morality is the Revised Reasons for Action Thesis, according to which any fact that is suitably related to some way in which A's $\phi$-ing (A's not $\phi$-ing) would be good (bad) is a reason for A to $\phi$. If it is false, then the Quick Argument is unsound. And, as I mentioned, I think that it is false.

We need to be careful, however, as to why it is false. It is important to note that the Revised Reasons for Action Thesis is only about facts about the ways in which an action can be good. It is not a thesis about the ways in which an artifact or a person can be good. It should be uncontroversial that facts about the ways in which an artifact or a person can be good are at best tangentially related to reasons for action. For example, the fact that a knife would be good for use in cutting vegetables is a reason for action only in a restricted set of circumstances. If there is no reason for anyone to cut vegetables, or if there is only a reason for people to cut vegetables poorly, then the fact that a knife would 
be good for use in cutting vegetables is simply irrelevant to what anyone ought to do. ${ }^{3 \mathrm{~B}}$ Similarly, the fact that Jones is good at hanging wallpaper is only tangentially related to reasons for action. But because such examples do not concern the ways in which an action can be good, they do not pose any difficulties for the Revised Reasons for Action Thesis

But is it true that any fact suitably related to some way in which an action, either A's $\phi$-ing or A's not $\phi$-ing, would be good of bad respectively is a reason for $A$ to $\phi$ ? Let us focus on one implication of the Revised Reasons for Action Thesis:

( $\mathrm{r}$ For any way of being good (bad), if it is a fact that A's $\phi$-ing (A's not $\phi$ ing) would be good (bad) in that way, then that fact is a reason for $A$ to $\phi$.

Now, $(\mathrm{I})$ is true only if all the ways in which an action can be good are, as I shall p"' it, necessarily normative. A way $\mathrm{W}$ of being good is necessarily normative if and only if the following condition holds of it:

For any agent $A$ and for any action $\phi$, if it is a fact that that A's $\phi$-ing would be good in way W, then that fact is a reason for $A$ to $\phi$.

For example, no matter who the agent or what the action, if it is a fact that that the agent's performing the action would be just, kind, or good for a person, then that fact intuitively seems to be a reason for the agent to perform that action. So being just, being kind, and being good for a person seem, intuitively, to be necessarily normative. Now, what ( $\mathrm{I}$ ) says is that all the ways in which an action can be good are necessarily normative, for what $(\mathrm{x})$ says is that for any way in which an action can be good, if $\mathrm{F}$ is the fact that A's $\phi$-ing would be good in that way, then F is a reason for $A$ to $\phi$. So $(x)$ is true if and only if all the ways in which an action can be good are necessarily normative.

But it isn't plausible to think that all the ways in which an action can be good are necessarily normative. For some of the ways of being goud, it can be a fact that some

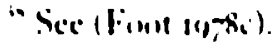


agent's action would be good in one of those ways even though that fact is not a reason for that agent to perform that action.

For example, let us suppose that Jones's saving a certain apple core in the freezer would be good for use as an example of something that only an obsessive person would do. Being good for use as an example is a way of being good. Hence, it is a fact that Jones's saving the apple core in the freezer would be good in that way. But if there is no reason to give anyone an example of something thai only an obsessive person would do, and there may well be no such reason, then the fact that Jones's putting the apple core in the freezer would be good in that way is not itself a reason for Jones to save the apple core in the freezer. So this is a counterexample to ( $\mathrm{I})$.

A second counterexample: suppose that my singing Jailhouse Rock would be a good impersonation of Elvis. A good impersonation is an impersonation that is good in some way. ${ }^{19}$ Hence, it is a fact that my singing Jailhouse Rock would be good in that way. But if there is no reason for me to impersonate Elvis, and there may well be no such reason, then the fact that my singing Jailhouse Rock would be good in that way is not itself a reason for me to sing Jailhouse Rock.

A third counterexample: suppose that my waving my arms in a certain way would be good to look at. Being good to look at is a way of being good. Hence, it is a fact that my waving my arms in that way would be good in that way. But if there is no one around to see me waving my arms, or if there are people around but they are just going to be annoyed by my waving my warms, then there may well be no reason for me to wave my arms.

So being good as an example of something only an obsessive person would do, being good as an impersonation of Elvis, and being good to look at are all ways in which 
an action can be good that are not necessarily normative. They arc thus counterexamples to the Revised Reasons for Action Thesis.

7.2 I mentioned that it seems plausible to think that being good for a person is necessarily normative: for any agent $A$ and any action $\phi$, any fact to the effect that $A$ 's $\phi$ ing would be good for a person is a reason for $\mathrm{A}$ to $\phi$. But what about being good for an artifact? It does not seem plausible to think that being good for an artifact is necessarily normative. For example, my removing a certain rust spot from my lawnmower might be good for it, but if the lawnmower is going to sit in my garage and never be used by anyone again, then there may well be no reason for me to do what would be good for my lawnmower. So in those circumstances, the fact that my removing the rust spot would be good for the lawnmower is not itself a reason for me to remove the rust spot. Hence, this is another counterexample to ( $\mathbf{I})$.

To take an even more vivid example, consider being good for a rubber band. My rubbing some oil on a certain rubber band might prevent it from becoming brittle, and so might be good for the rubber band. But plainly, if no one is ever going to use that particular rubber band for anything, then there is no reason for me to do what would be good for it. So this is another counterexample to $(\mathrm{I})$.

When is a fact that an action would be good for an artifact a reason for action? I suggest the following generalization:

The Good for an Artifact Generalization: The fact that A's $\phi$-ing would be good for an artifact is a reason for $A$ to $\phi$ if and only if there is a reason for $A$ to do what would be conducive to the artifact's being in a good condition.

And the interesting thing to note about the Good for an Artifact Generalization is that analogous principles hold of other ways in which an action would effect an artifact. For example, the fact that Alfred's using the tray of his CD-ROM drive as a drinkholder would be destabilizing for his CD-ROM drive is a reason for hum to use the trily 
as a drink-holder if and only if there is a reason for him to do what would be conducive to his CD-ROM drive's being in a destabilized condition. The fact that Alfred's using the tray of his CD-ROM drive as a drink-holder would be bad for his CD-ROM drive is a reason for him to use it as a drink-holder if and only if there is a reason for him to do what would be conducive to his CD-ROM drive's being in a bad condition. But if the relationship between reasons for action and being good for an artifact is no different from the relationship between reasons for action and being destabilizing or bad for an artifact, then being good for an artifact bears no interesting relationship to reasons for action.

7.3 There is no need to make an exhaustive examination of all of the ways of being good and their relation to reasons for action. The examples just given suffice to show that not all of the ways in which an action can be good are necessarily normative. Thus, the second premise of the Quick Argument for the Relevance of Morality, the Revised Reasons for Action Thesis, is false, and the argument is unsound.

\section{The Revised Argument for the Relevance of Morality}

8.I But as I mentioned, it is intuitively plausible to think that some ways of being good are necessarily normative. What the above counterexamples show is only that not all the ways of being good are necessarily normative. They do not show that none of the ways of being good are necessarily normative.

We have been focusing on the ways of being good, but analogous principles can be constructed for the ways of being bad. Let us say that a way $\mathrm{W}$ of being bad is necessarily normative if and only if the following condition holds:

For any agent $A$ and for any action $\phi$, if it is a fact that that $A$ 's not $\phi$-ing would be bad in way $W$, then that fact is a reason for $A$ to $\phi$. 
Examples analogous to the ones given in the previous section will show that not all of the ways in which an action can be bad are necessarily normative. But, again, some ways of being bad seem, intuitively, to be necessarily normative. For example, being bad for a person seems to be necessarily normative: for any agent $A$ and for any action $\phi$, if it is a fact that A's not $\phi$-ing would be bad for a person, then that fact is a reason for $A$ to $\phi$.

If we could come up with an account which distinguished the necessarily normative ways of being good or bad from the contingently normative ways of being good or bad, and if it could be shown that facts about the ways in which a vicious action would be bad are necessarily normative, then we would have a revised argument for the Relevance of Morality.

So how do we mark off the necessarily normative from the contingently normative? Further, how do we establish that any action that is vicious is bad in a way that is necessarily normative? Why couldn't it turn out, for example, that the fact that Alfred's not returning the money would be unjust fails to be a reason for him to return the money, even granting that being unjust is a way of being bad?

8.2 One story might go as follows. The reason why being good for a person is necessarily normative whereas being good for an artifact is only contingently normative presumably has something to do with a difference between people and artifacts. And it would be no surprise if that difference was expressed by saying that people are intrinsically valuable, valuable in themselves, whereas artifacts, if they are valuable at all, are only extrinsically valuable, valuable as a means. ${ }^{40}$

\footnotetext{
${ }^{40}$ Are there things other than people that are intrinsically valuable? On some views, all sentient creatures are intrinsically valuable. On other views, all rational creatures are intrinsically valuable. ( $n$ still other views, all life is intrinsically valuable. It wouldn't surprise me if those who thought that thing" belonging to a class $C$ are intrinsically valuable also theught that facts we the effect that $A$ 's 0 -ing wimbld he gond or bad for something in class $C$ were always reasons for $A$ to 0 . Further, it is plausible w think thin

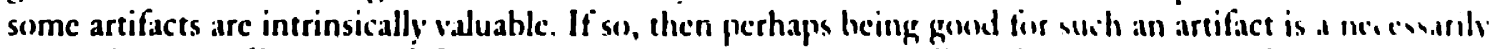

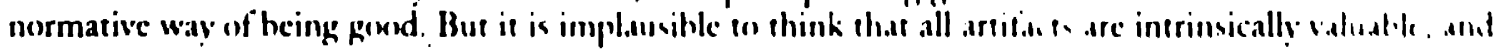


Suppose it is true that people are intrinsically valuable, and that being good for something that is intrinsically valuable is necessarily normative. That is, if $\mathrm{x}$ is intrinsically valuable, then for any agent $A$ and action $\phi$, if it is a fact that $A^{\prime} s \phi$-ing would be good for $x$, then that fact is a reason for $A$ to $\phi$. If we could also help ourselves to a popular thesis about harmless wrongdoing, we would have a new argument for the Relevance of Morality that did not rely on the dubious supposition that all the ways in which an action can be good or bad are necessarily normative. The popular thesis I have in mind is simply that there is no harmless wrongdoing, by which I mean that any action that would be vicious would be bad for a person. The new argument would then go as follows. People are intrinsically valuable. If people are intrinsically valuable, then the fact that an agent's action would be bad for a person is a reason for that agent to refrain from that action. Hence, the fact that an agent's action would be bad for a person is a reason for that agent to refrain from that action. But there is no harmless wrongdoing: if an action would be vicious, then that action would bu bad for a person. Since the Moral Requirements Thesis says that morality requires an agent to do something if and only if the agent's not doing that thing would be vicious, it follows that if morality requires an agent to not do a thing, then the agent's doing that thing would be bad for a person. Since being bad for a person is being bad for something intrinsically valuable, it follows that if morality requires an agent to do something, there is a reason for that agent to do that thing.

This revised argument for the Relevance of Morality can be stated more formally as follows:

so it is implausible to think that heing gond for an arrifict is ieself at necessarily normunive wav of heing good. 


\section{The Revised Argument for the Relevance of Morality}

(PI) People are intrinsically valuable.

$\left(\mathrm{P}_{2}\right)$ If people are intrinsically valuable, then being bad for a person is necessarily normative.

(ICI) Hence, if it is a fact that A's not $\phi$-ing would be bad for some person, then that fact is a reason for $A$ to $\phi$. (From $P_{1}$ and $P_{2}$ )

$\left(P_{3}\right)$ If morality requires $A$ to $\phi$, then $A$ 's not $\phi$-ing would be vicious.

$\left(\mathrm{P}_{4}\right)$ If $A$ 's not $\phi$-ing would be vicious, then it is a fact that $A$ 's not $\phi$-ing would be bad for some person.

(IC2) Hence, if morality requires $A$ to $\phi$, it is a fact that $A$ 's not $\phi$-ing would be bad for some person. (From $\mathrm{P}_{3}$ and $\mathrm{P}_{4}$ )

(C) Hence, if morality requires $A$ to $\phi$, there is a reason for $A$ to $\phi$. (From IC and $\mathrm{IC}_{2}$ )

8.3 Let me review where we are. We had the Quick Argument for the Relevance of Morality, which went as follows. If morality requires $A$ to $\phi$, then $A$ 's not $\phi$-ing would be vicious in some way. The ways of being vicious are ways of being bad, and so are ways of being morally bad. But if it is a fact that A's not $\phi$-ing would be bad in some way, then there is a reason for $A$ to $\phi$. Hence, if morality requires $A$ to $\phi$, there is a reason for A to $\phi$. But the argument was unsound, for not all the ways of being good nor all the ways of being bad are necessarily normative, and so it could be a fact that A's not $\phi$-ing would be bad in some way even though that fact was not a reason for $A$ to $\phi$. For example, it could be a fact that my leaving the rust spot on my lawnmower would be bad for it even though there is no reason for me to remove the rust spot. Being bad for an artifact is not a way of being bad that is necessarily normative.

But being good for a person does seem to be necessarily normative. So I asked: what is the difference? One natural suggestion is that the difference lies in a difference between people and artifacts, a difference which might be expressed by the thought that people are intrinsically valuable whereas artifacts, if valuable at all, are only extrinsically valuable. According to this suggestion, then, being good for something that is intrinsically valuable is a necessarily normative way of being good, and heing bad for something that is intrinsically valuable is a necessarily normative way of heing bad. So if 
we can suppose that people are intrinsically valuable, and if we can also suppose that morality requires an action only if refraining from that action would be bad for a person, then we have a revised argument for the Relevance of Morality, an argument which bypasses the objection to the Quick Argument for the Relevance of Morality.

\section{Difficulties for the Revised Argument for the Relevance of Morality}

9.I I think there are two problems with the Revised Argument for the Relevance of Morality. Let me begin with a problem for $\left(\mathrm{P}_{4}\right)$, which says that if A's not $\phi$-ing would be vicious, then it is a fact that A's $\phi$-ing would be bad for some person. ${ }^{41}$ As I mentioned, many people find this view plausible. Many people also find a stronger view plausible: many people find it plausibie to think that actions that are vicious arc bad for someone other than the agent performing the action. Harm to oneself, on this view, may be bad in some way, but it isn't vicious. I have sympathy for the stronger view, but what causes trouble for it, and for $\left(\mathrm{P}_{4}\right)$, are vicious paternalistic actions. My not giving Jones his cigarettes back when he asks for them might be good for Jones, and bad for no one else, but it might nonetheless be unjust because the cigarettes belong to Jones.

9.2 There is a second problem, which I think is more serious.

According to the first premise of the Revised Argument for the Relevance of Morality, people are intrinsically valuable. But what is it to be intrinsically valuable? Some philosophers would analyze intrinsic value in terms of reasons for action: an object $\mathrm{x}$ is intrinsically valuable if and only if, facts that A's $\phi$-ing (A's not $\phi$-ing) would be good (bad) for $\mathbf{x}$ are always a reason for $A$ to $\phi$. If we opt for this analysis of intrinsic

\footnotetext{
"It should be noted that $\left(\mathrm{P}_{4}\right)$ does not say that if an action is immoral, then it is, on lialienci, fiod for pcoplc. That would be objectionable to any nonconsequentialist. An action can be unjust, and yet be, oin balance, good for people. Dissecting Jones without his consent in order to distrilute his organis to five people who need the on to live might be, on balance, goond for perople (the gond fier the live mighe enerweigh the bad for Jones), hut it is still unjust, and hence, is still immor.al
} 
value, then we have gone in a circle, for we were trying to use the claim that people arc intrinsically valuable as an explanation of why being good for a person and being bad for a pers $n$ are necessarily normative. That is, if we analyze intrinsic value in this way, then to say that people are intrinsically valuable just is to assert the claim in need of explanation.

An alternative analysis of intrinsic value would say that a thing is intrinsically valuable if and only if it is intrinsically good, good solely in virtue of what it is, independently of its relation to other things. But this analysis can't be right because there is no such thing as goodness.

Alternatively, we might define intrinsic value by saying that a thing is intrinsically valuable if and only if it is intrinsically good in some way, that is, good in some way solely in virtue of what it is, independently of its relation to other things. But as I will now argue, defining intrinsic value in this way makes it implausible to think that people are intrinsically valuable.

If we define intrinsic valıe by saying that a thing is intrinsically valuable if and only if it is intrinsically good in some way, then in order to make it out that people are intrinsically valuable, it needs to be made out that each person is intrinsically good in some way. A fortiori, it needs to be made out that each person is good in some way. Well, consider Jones. Jones is, as some would say, "a good for nothing bum." He isn't just, nor is he kind or considerate, nor is he pleasant or graceful. And he isn't good at anything either. In what way is Jones good? And consider Jones's friend, Smith. In what way is Smith good? Is Smith good in the same way in which Jones is good, or is he good in a different way? Presumably, it is the same way for all people. If so, then in what way are all people good? They aren't all just, nor are they all considerate, and so on for the other ways of being good. Intuitively, it seems that for any way of being geod, there could be a person who was not good in that way. 
The only way I can see of securing that all people are good in some way is to suppose that being a person is itself a way of being good. So perhaps those who think that people are intrinsically valuable would say that being a person is itself a way of being good. Even if Jones is neither just nor pleasant nor..., perhaps those who think that people are intrinsically valuable would nonetheless say that he is at least good in this way: he is a person. And, it could be added, people are good in that way solely in virtue of facts about what it is to be a person, independently of their relation to other things. So, perhaps those who think that people are intrinsically valuable would say that the way in which people are intrinsically good is simply that they are people.

But is being a person a way of being good? Sometimes, when someone says 'Jones is a person', we might reply by saying 'Thai's good', but that doesn't show that being a person is a way of being good. Sometimes, when someone says 'Jones is tall', we might reply by saying 'That's good', but that doesn't show that being tall is a way of being good. It seems manifestly implausible to think that being a person is a way of being good.

Isn't someone who is tempted to say that being a person is a way of being good really just expressing their confidence that facts to the effect that an action would effect the well-being of that person are reasons? But then, just as with the analysis of intrinsic value in terms of reasons for action, we have gone in a circle. We were looking for an explanation which would provide a basis for the claim that being good for a person is a necessarily normative way of being good, not merely an expression of confidence that it is. Without a general account of what marks something as a way of being good or as a way of being bad, we are in danger of being able to make claims that, while they would guarantee the conclusion we wanted, would be so ad hoc as to deprive the argument of any independent force. 
9.3 The objection I pressed against the Quick Argument for the Relevance of Morality was that the Revised Reasons for Action Thesis implied that all the ways of being good and all the ways of being bad are necessarily normative, and that this seemed manifestly implausible. Some ways of being good and some ways of being good are only contingently normative. But all that we need to secure the Relevance of Morality is that the ways in which a vicious action are bad are necessarily normative. The Revised Argument for the Relevance of Morality tried to give such an argument by claiming that people were intrinsically valuable, and that vicious actions are always bad for someone. But the argument required implausible ad boc assumptions about the ways of being good, and it required denying that there could be wrongful paternalistic actions.

There are a number of responses that could be made at this point. Perhaps being a person really is a way of being intrinsically good. If so, then we need an account of what marks it as such. Perhaps all people are intrinsically good in some way, even though being a person isn't itself an intrinsic way of being intrinsically good. If so, then it needs to be made out in what other way all people are intrinsically good. Or, perhaps people are intrinsically valuable, even though they are not all intrinsically good in some way. If so, then intrinsic value is not to be defined in terms of being intrinsically good in some way, and it needs to be made out what intrinsic value is. Or, perhaps what explains why being good for a person and being bad for a person are necessarily normative is not that people are intrinsically valuable. If so, then it needs to be made out what the difference is between people and artifacts that makes it the case that being good for a person and being bad for a person are necessarily normative, whereas being good for an artifact is not.

I don't say these responses can't be made out, only that I don't see how they will be. 


\section{ro Summary and Concluding Remarks}

ro.I Morality is relevant to what an agent ought to do. Why?

An account of reasons for action that is based on the ways of being good holds out promise for securing the Relevance of Morality in an attractive way. Drawing largely from Thomson's views, I sketched an account according to which a fact is a reason for an agent to perform an action if and only if it was suitably related to some way in which the action would be good, or if it was suitably related to some way in which refraining from the action would be bad. This account had a number of attractions. It provided an intuitively attractive account of how there can be a reason for an agent to perform an action even though the action would not be good for that very agent; it is enough that it be good for someone else. Moreover, the account was compatible with the fact that an agent can take, something to be a reason for action without believing that the action would be good.

That account provided the premises for what I called the Quick Argument for the Relevance of Morality. If facts about the ways in which refraining from an action would be bad are reasons for performing that action, and if morality requires refraining from acts that are bad in some way, then there would always be a reason for agents to comply with their moral requirements. But $I$ argued that not all the ways in which an action can be bad are necessarily normative. So the Quick Argument for the Relevance of Morality was unsound.

I then explored one possible revision of that argument. If it could be made out that being bad for a person is a way of being bad that was necessarily normative, and if it could be made out that vicious actions were always bad for a person, then we would have an argument for the Relevance of Morality that bypasses the objection to the Quick Argument. But I noted that not all vicious actions are bad for a person, and I argued against one attempt to use the notion of intrinsic value to establish that being bad for a person is a way of being bad that is necessarily normative. 
10.2 Clearly, a friend of the story I have been exploring needs some explanation of the distinction between the ways of being good or bad that are necessarily normative and those that are only contingently normative. I argued against one possible explanation, but intuitively some ways of being good or bad are necessarily normative. The problem is giving a plausible explanation of that intuition.

Further, a friend of the story I have been exploring needs an account of what marks something as a way of being good. That being kind is a way of being good is intuitively plausible, but presumably is susceptible to some explanation. Further, there are skeptics about morality who claim that the ways in which an action can be virtuous are not ways of being good. Without an account of what marks something as a way of being good, the response to such skeptics has to rely largely on intuitions that the skeptic claims not to share. And finally, there are hard cases about which one doesn't have to be a skeptic to be worried. Is being chaste a way of being good? What about being humble? Some say they are, but some say they are not. An account of what marks something as a way of being good would help resolve these issues. 


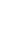




\section{References}

Abell, George O. 1982. Exploration of the Universe. Fourth edition. Los Angeles: Saunders College Publishing.

Anscombe, G. E. M. 1958. "On Brute Facts" Analysis 18: 69-72.

Baker, Robert H. 1946. Astronomy. Fourth edition. New York: D. Van Nostrand Company, Inc.

Brink, David. 1997. "Moral Motivation." Ethics ro8: 4-32.

Brower, Bruce W. 1988. "Virtue Concepts and Ethical Realism." The Journal of Philosophy 85: 675-693.

Dreier, James. 1990. "Internalism and Speaker Relativism." Ethics ror: 6-26.

Einstein, Albert. 196r. Relativity. New York: Crown Publishers, Inc.

Feynman, Richard P. 1995. Six Easy Pieces. Reading, Massachusetts: Addison-Wesley Publishing Company.

Foot, Philippa. 1967. Theories of Ethics. New York: Oxford University Press.

Foot, Philippa. 1978a. Virtues and Vices and Other Essays in Moral Philosophy. Oxford: Basil Blackwell.

Fcot, Philippa. 1978b. "Are Moral Considerations Overriding?" in (Foot 1978a).

Foot, Philippa. 1978c. "Goodness and Choice", reprinted in (Foot 1978a).

Foot, Philippa. 1978d. "Virtues and Vices," reprinted in (Foot 1978a).

Foot, Philippa. 1972. "Morality as a System of Hypothetical Imperatives," reprinted (with revisions) in (Foot 1978a)

Geach, Peter. 1956. "Goodness and Evil," in (Foot 1967).

Harman, Gilbert, and Thomson, Judith Jarvis. 1996. Moral Relativism and Moral Objectivity. Edited by E. Sosa, Great Debates in Pbilosophy. Cambridge, Massachusetts: Blackwell Publishers Ltd.

Harman, Gilbert. 1975. "Moral Relativism Defended." Reprinted in Relativism: Cognitive and Moral. Edited by Michael Krausz and Jack W. Meiland. Notre Dame, Indiana: University of Notre Dame Press. 1982. 
Harman, Gilbert. 1977. The Nature of Morality: An Introduction to Ethics. New York: Oxford University Press.

Harman, Gilbert. 1978. "Relativistic Ethics: Morality as Politics." In Midwest Studies in Philosophy III: Studies in Ethical Theory. Edited by Peter A. French, Theodore E. Uehling, Jr., and Howard K. Wettstein. Minneapolis: University of Minnesota Press. 5978 .

Harman, Gilbert. 1978. "What Is Moral Relativism?" In Values and Morals, edited by A. I. Goldman and J. Kim. Dordrecth, Holland: D. Reidel Publishing Company.

Harman, Gilbert. 1984. "Is There A Single True Morality?" Reprinted in Relativism: Interpretation and Confrontation. Edited by Michael Krausz. Notre Dame, Indiana: University of Notre Dame Press. I989.

Harman, Gilbert; and Thomson, Judith Jarvis. 1996. Moral Relativism and Moral Objectivity. Edited by E. Sosa, Great Debates in Philosophy. Cambridge, Massachusetts: Blackwell Publishers Ltd.

Hoskins, Michael. 1997a. "From Geometry to Physics: Astronomy Transformed." In Astronomy. Edited by Michael Hoskins. Cambridge, United Kingdom: Cambridge University Press.

Hoskins, Michael. 1997b. "The Astronomy of the Universe of Stars" in Astronomy. Edited by Michael Hoskins. Cambridge, United Kingdom: Cambridge University Press.

Hursthouse, Rosalind; Lawrence, Gavin; and Quinn, Warren. 1995. Virtues and Reasons: Philippa Foot and Moral Theory. Oxford: Clarendon Press.

Kaplan, David. 1977. "Demonstratives: An Essay on the Semantics, Logic, Metaphysics, and Epistemology of Demonstratives and Other Indexicals" in Themes from Kaplan, edited by J. Almog, J. Perry, and H. Wettstein. Oxford: Oxford University Press. 1989.

Korsgaard, Christine. 1966. The Sources of Normativity. Cambridge, United Kingdom: The Press Syndicate of the University of Cambridge.

Lawrence, Gavin. 1995. "The Rationality of Morality" in (Hursthouse, Lawrence, and Quinn 1995).

Lyons, David. 1976. "Ethical Relativism and the Problem of Incoherence." Reprinted in Relativism: Cognitive and Moral, edited by J. W. Meiland and M. Krausz. Notre Dame, Indiana: University of Notre Dame Press. 1982.

Mackic, J. L. 1977. Ethics: Inventing Right and Wrong. London: Penguin Books.

Newton, Isaac. 1966. Principia. Third edition. Berkeley and Los Angeles, California: University of California Press. 
Stampe, Dennis. 1987. “The Authority of Desire." The Philosophical Review 96: 335-38r.

Thomson, Judith Jarvis. 1983. "Imposing Risks." Reprinted in Rights, Restitution, ard Risk. Edited by William Parent. Cambridge, Massachusetts: Harvard University' Press. 1986.

Thomson, Judith Jarvis. 1990. The Realm of Rights. Cambridge, Massachusetts: Harvard University Press.

Thomson, Judith Jarvis. 1992a. "Goodness and Utilitarianism." Paper read at the Eighty-Ninth Annual Eastern Division Meeting of the American Philosophical Association, at Washington, D. C.

Thomson, Judith Jarvis. 1992b. "Some Ways in Which a Thing Can Be Good." Social Philosophy and Policy 9: 96-Ir7.

Thomson, Judith Jarvis. 1997. "The Right and the Good." The Journal of Philosophy 94: 273-298.

Thomson, Judith Jarvis. 1999. "Desire and the Good." Paper read at the 1999 Central Meeting of the American Philosophical Association, at New Orleans, Louisiana.

Von Wright, G. H. 1963. The Varieties of Goodness. London: Routledge.

Williams, Bernard. 1976. "Moral Luck." Reprinted in Moral Luck. Cambridge, United Kingdom: Cambridge University Press. 198r.

Williams, Bernard. 1989. "Internal Reasons and the Obscurity of Blame." Reprinted in Making Sense of Humanity. Cambridge, United Kingdom: Cambridge University Press. 1995.

Wolf, Susan 1982. "Moral Saints." Journal of Philosophy 79: 419-439.

Wong, David. 1984. Moral Relativity. Berkeley: University of California Press.

Ziff, Paul. 1960. Semantic Analysis. Ithaca, New York: Cornell University Press. 